\title{
مهارات الإتصال وعلاقتها بقدرة ربة الأسرة على مواجهة الضغوط الأسرية
}

$$
\text { إعداد ربة رالاد }
$$

\section{د/ نهى عبد الستار عبد المحسن}

مدرس إدارة المنزل والمؤسسات

كلية الاقتصاد المنزلي · جامعة المنوفية

\section{د/أميرة حسان عبد الجيد دوام}

مدرس إدارة المنزل والمؤسسات

كلية الاقتصاد المنزلى · جامعة المنوفية

\section{الملخص}

يحتاج الانسان فى كل حالاته الى أن يتصل بالآخرين من البشر فالحاجة الى الاتصـال يولد بها الفرد

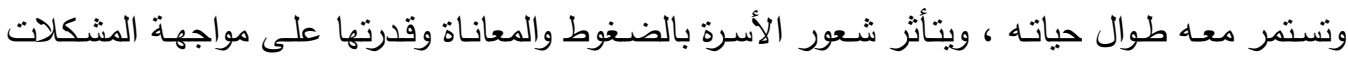

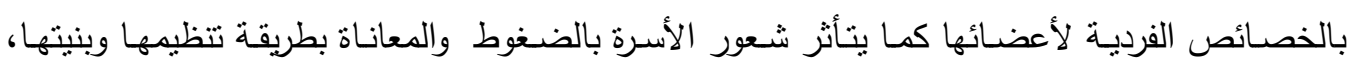

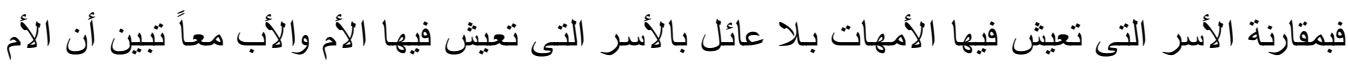

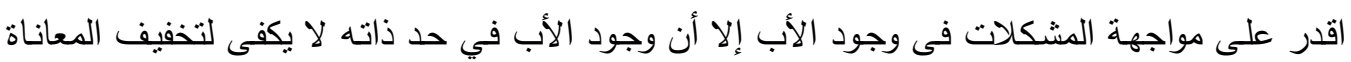

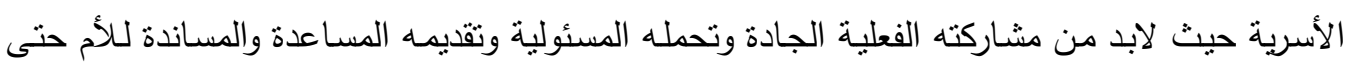
يمكن التخفيف من وطأه الشعور بالضغوط، ولهذا استهدف البحث الحالي دراسة العلاقة بين مهارات

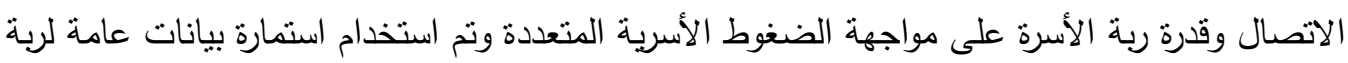

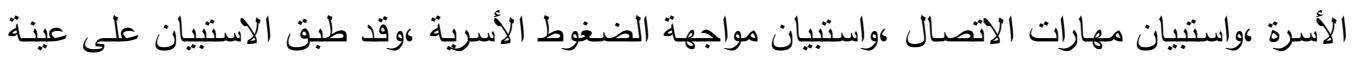

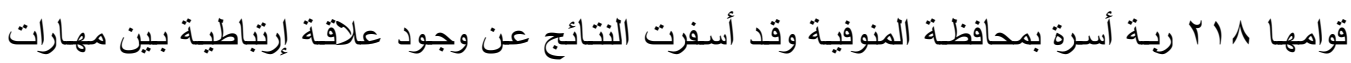

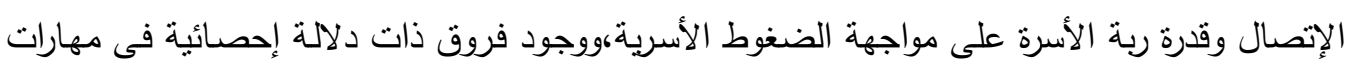

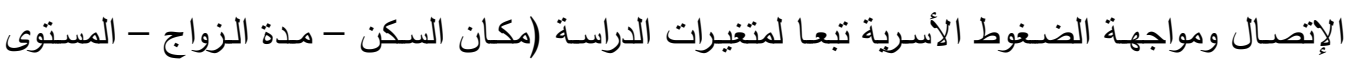
التعليمى للزوج والزوجة - عمل الزوجة - حجم الأسرة). 
مهارات الإتصال وعلاقتها بقدرة ربة الأسرة على مواجهة الضغوط الأسرية إعداد

\section{د/ نهى عبد الستار عبد المحسن}

مدرس إدارة المنزل والمؤسسات

كلية الاقتصاد المنزلي · جامعة المنوفية
د/أميرة حسان عبد الجيد دوام

مدرس إدارة المنزل والمؤسسات

كلية الاقتصاد المنزلى · جامعة المنوفية

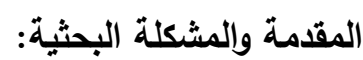

يعكس التواصل الإنساني حيوية البشر وديناميكية علاقاتهم ببعضهم البعض ويعد التواصل بين الثُعوب

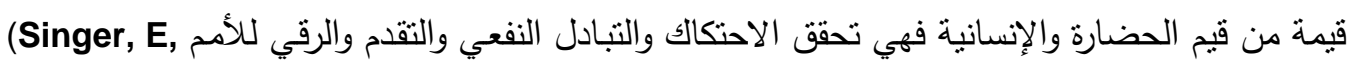

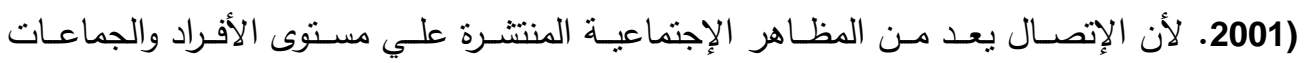

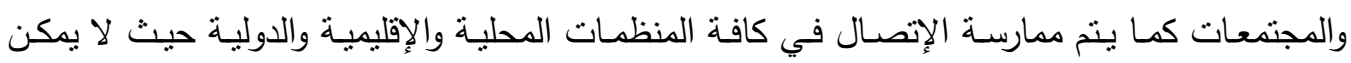
تصور وجود إنسان يعيش بمفرده أو بعيد عن الأحداث التي تدور في المجتمع كما أن الفرد لا يستطيع التهات

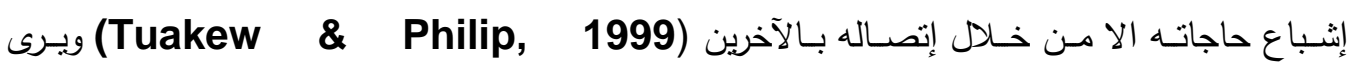
أن الأتصال يعمل علي تدعيم شبكة العلاقات الاجتماعية

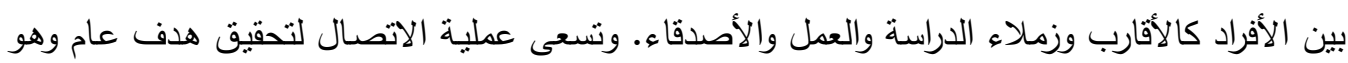

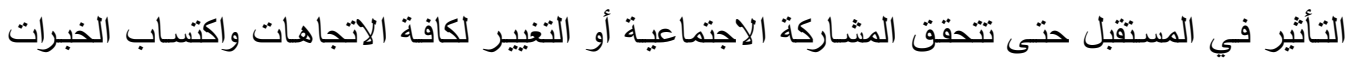

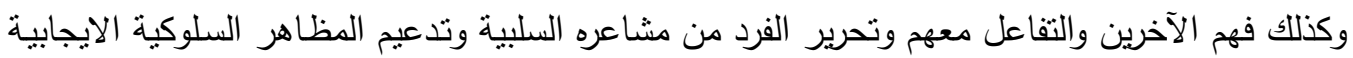

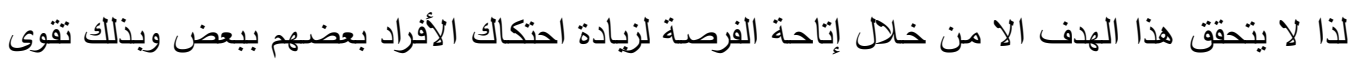
الصلات الاجتماعية بينهم (عبد العزيز السرطاوي وجميل الصمادي، و91911).

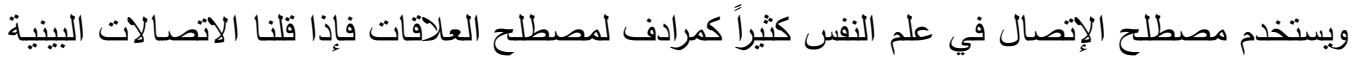

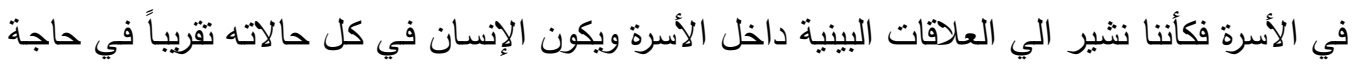
الي أن يتصل بالآخرين من البشر فالحاجة الي الاتصال يولد بها الفرد وتستمر معهد طوال حياته (علاء الأ الاين كفافى، 999 1 )،وتبدأ عملية الاتصال البشري منذ الولادة فيصدر الوليد منذ اللحظة الأولى لولادته

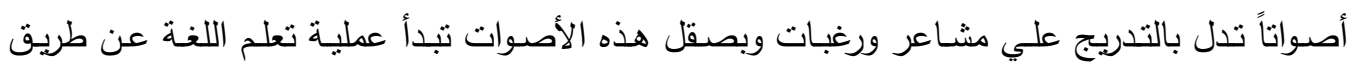

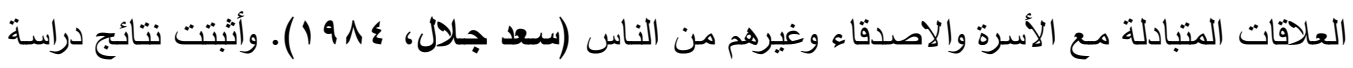
إيمان جلبط (11 + Y) أن هناك علاقة ارتباطية ايجابية بين وعى الأم بمهارة الاتصال في تربية الأبناء

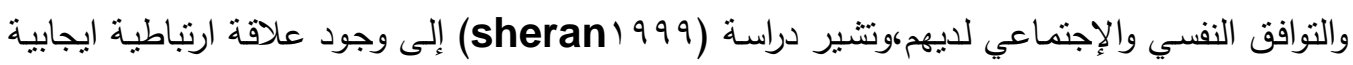
بين الإتصال الاجتماعي بين الأم والطفل ونمو مهاراته اللغوية في المنزل حيث توجد علئ علاقة بين بين معدل الاتصال بين الطفل والقائمين على رعايته وتربيته والكفاءة الاجتماعية واللغوية للطفل. 
والعلاقات الأسرية لها أغلب الأهميـة والتأثثر علي حياتتا فنتعلم من خلالها الكثير ممـا نعرفهـ عن

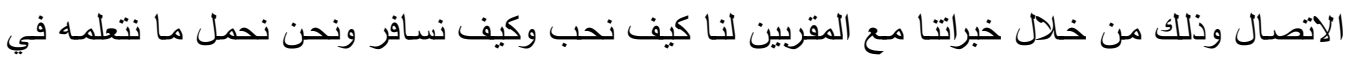

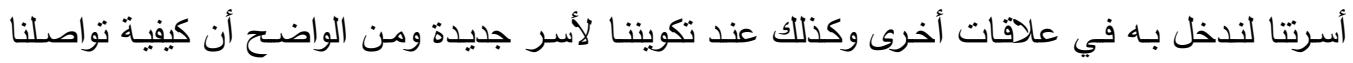

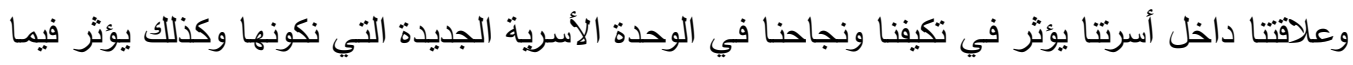

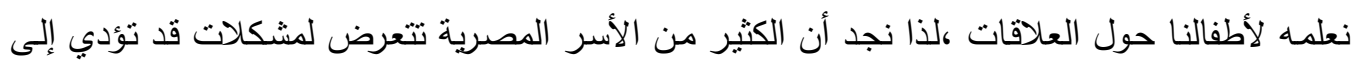

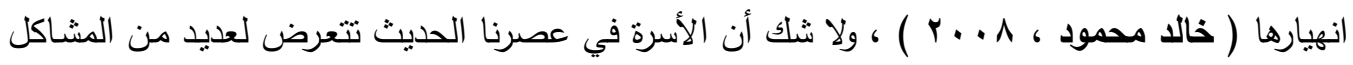

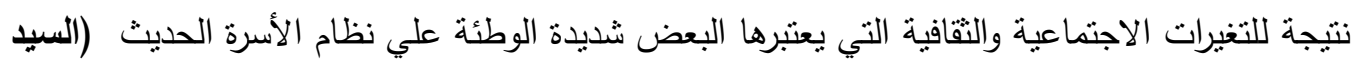

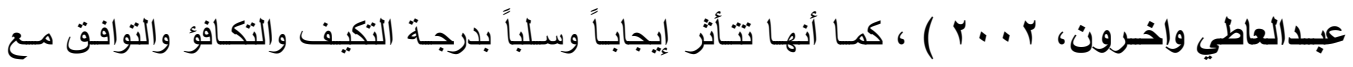
التغيرات التي تحدث في بناءها ومدى القدرة علي المواءمة بين الأهداف المستقبلية والظروف المرحلية ،

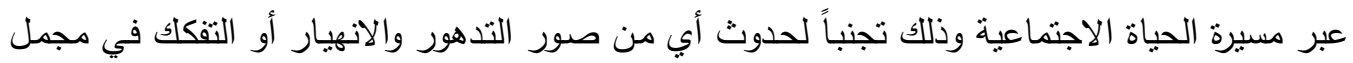

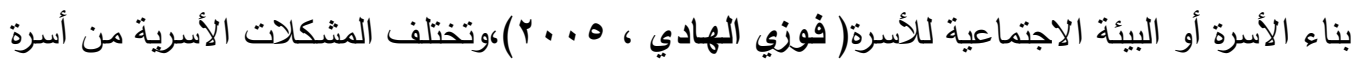

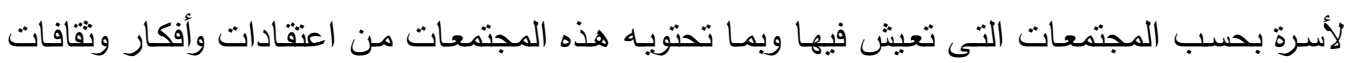

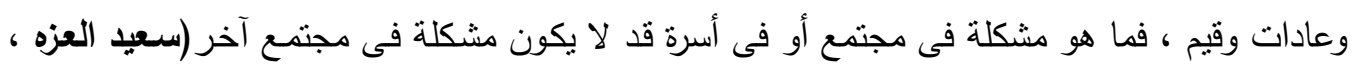
. (r...

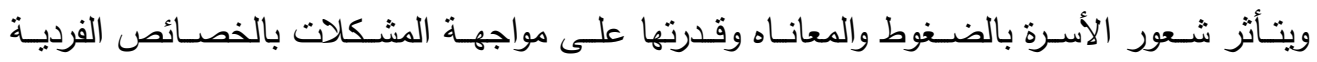
لأعضائها منل: درجة ذكاء الأفراد وأسلوب تفكيرهم وسماتهم الثخصية وبطبيعة العلاقات السائدة بينهم

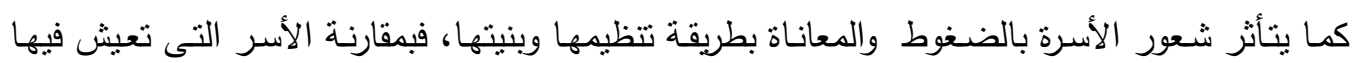

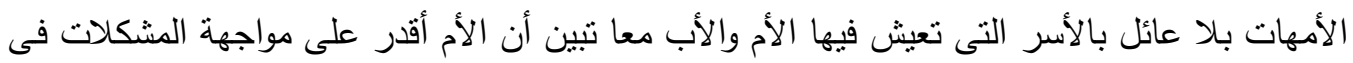

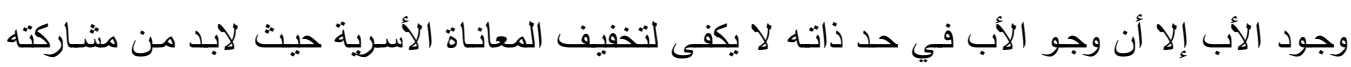

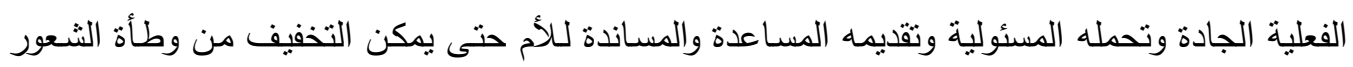

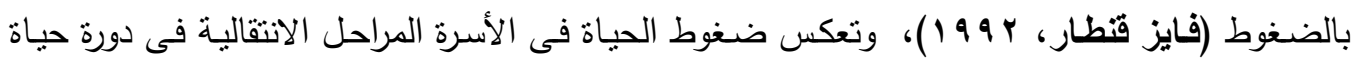

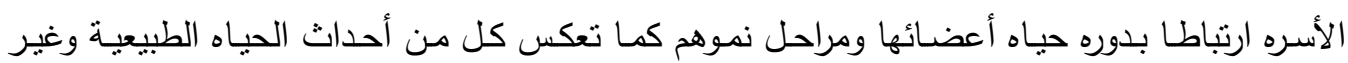

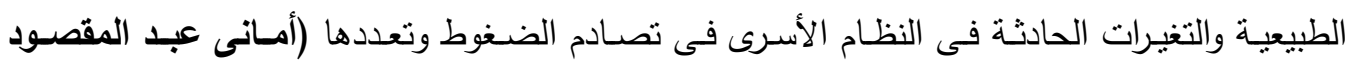
. (r...v كما أثتبت نتائج دراسة محمد الثيخ (1990) (190 أن هناك علاقة ارتباط إيجابية بين النوافق النفسي

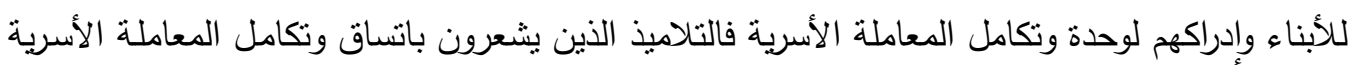

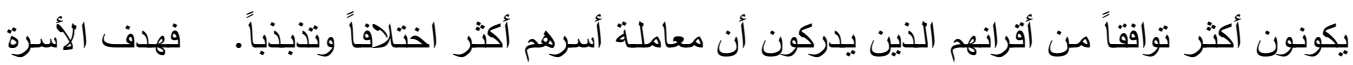

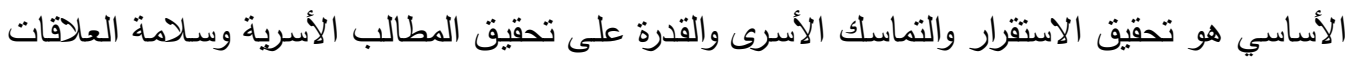


بين الوالدين والأولاد وبعضهم حيث يسودها الحب والثقة والاحترام المتبادل بين جميع أفراد الأسرة وكذلك

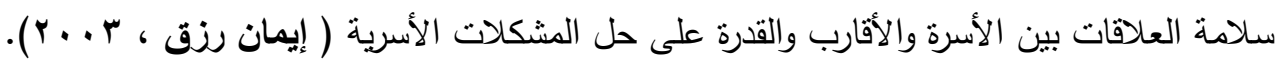
ويناعاً على ما سبق يمكن صياغة مشكلة البحث الحالي فيما يلي :-

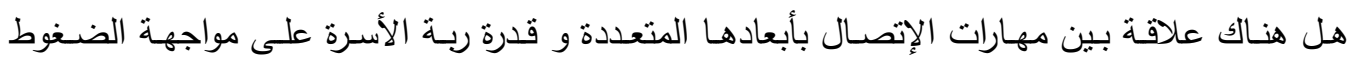

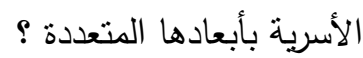
أهداف البحث: يهدف البحث بصفة رئيسية إلى دراسـة مهارات الاتصـال الأسرى وعلاقتها بقدرة ربـة الأسرة على مواجهة الضغوط الأسرية ولتحقيق هذا الهذف بستلزم تحقيق الأهداف الفرعية التالية :

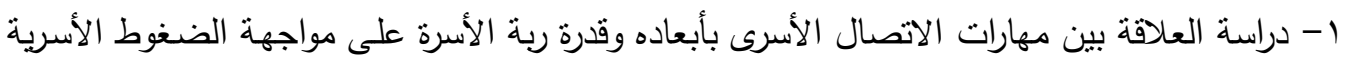
بأبعادها.

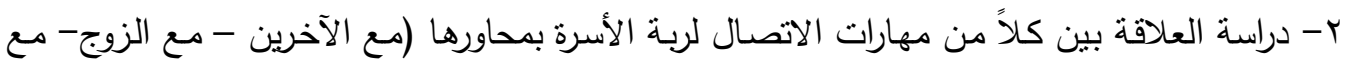

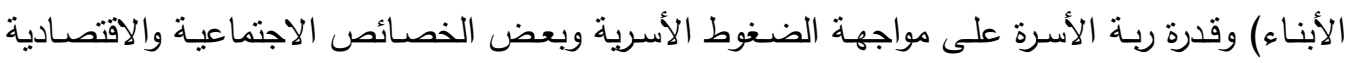

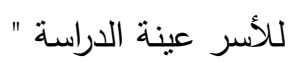

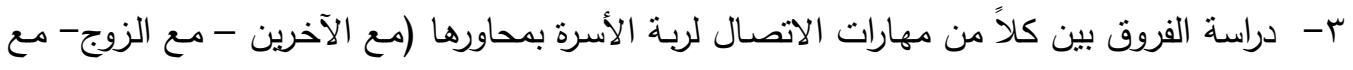

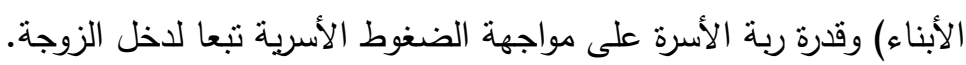

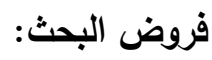
ا- توجد علاقة ارتباطية ذات دالالة احصائية بين مهارات الاتصال بمحاورها مع الآخرين- مع الزوجمع الأبناء) وقدرة ربة الأسرة على مواجهة الضغوط دأل الأسرية بمحاورها (اجتماعية- اقتصادية- نفسيةصحية- دينية واخلاقية). r- توجد علاقة ارتباطية ذات دلالة إحصائية بين مهارات الاتصال لربة الأسرة بمحاورها (مع الآخرين - مع الزوج- مع الأبناء) وبعض الخصائص الاجتماعية والاقتصادية للأسر عينة الدراسة.

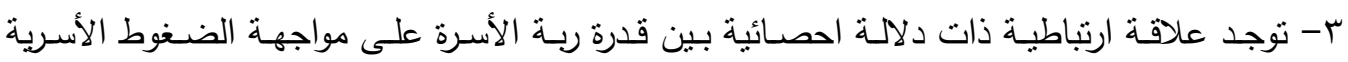

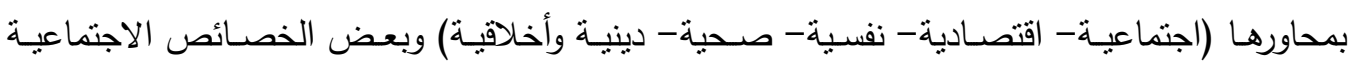
والاقتصادية للأسر عينة الدراسة. ع - توجد فروق ذات دلالـة إحصائية في مستوى مهارات الاتصـال لربـة الأسرة وقدرتها على مواجهة الضغوط الأسرية تبعاً لاخل الزوجة. 
ثانيا: مصطلحات الاراسة:

الاتصال: لغة التفاهم والتحاور بين أفراد الأسرة التي تتقل أفكار كل منهم ومشاعره ورغباته واهتماماته

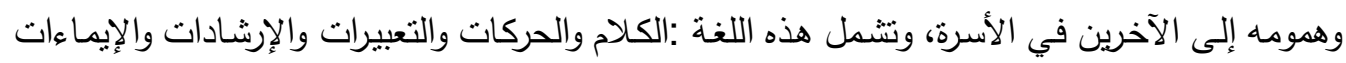

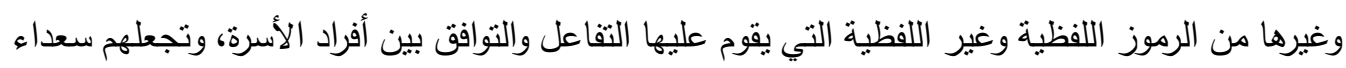

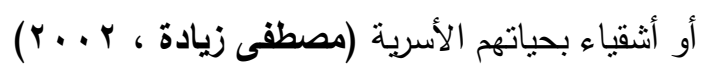

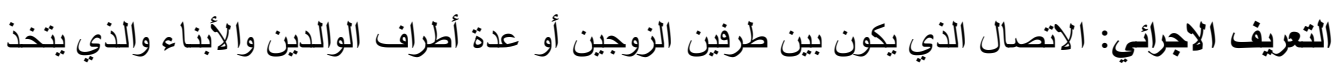

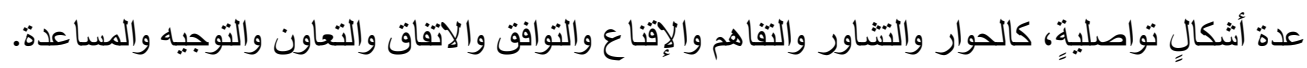

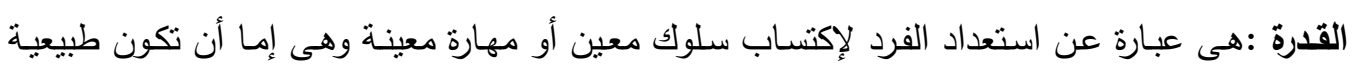
نتيجة موهبة طبيعية فى الانسان أو تكون مكتسبة إذا اعطى التدريب المناسب.

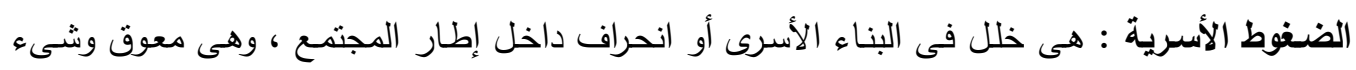

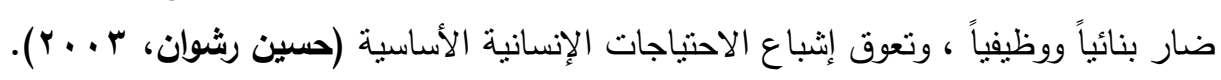

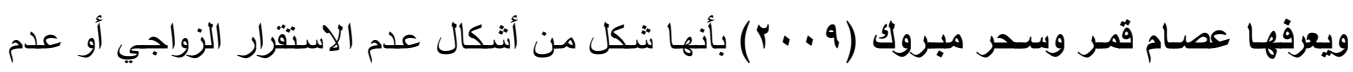
اتفاق الزوجين أو بين أحد منهما مع الأبناء ، مما يؤثر سلباً في شبكة العلاقات الأسرية.

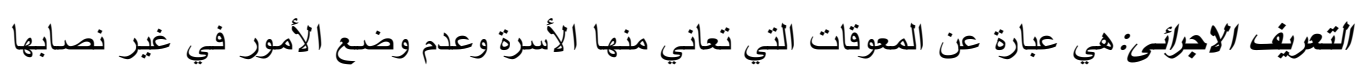

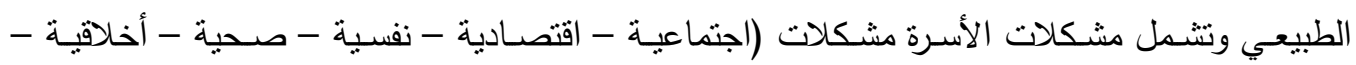
ودينية ). ثالثا:عينة البحث:

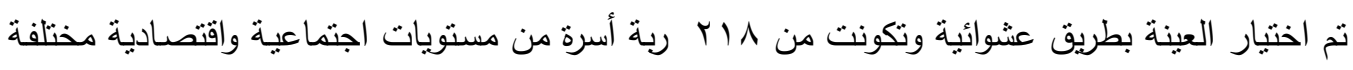
ومن محافظة المنوفية. رابعا: إعداد ويناء أدوات الدراسة: - أولا:استمارة البيانات العامة للأسرة :

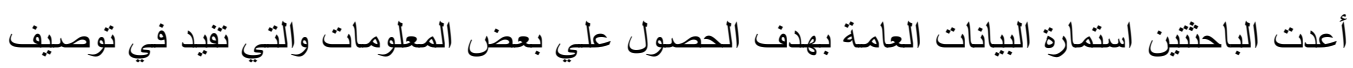

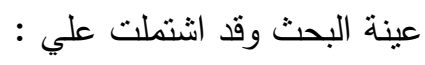

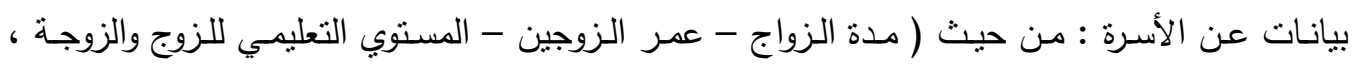

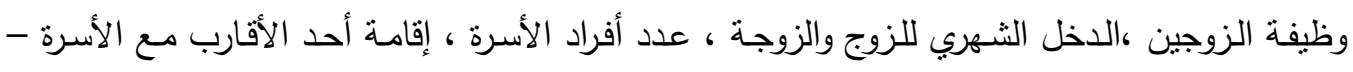

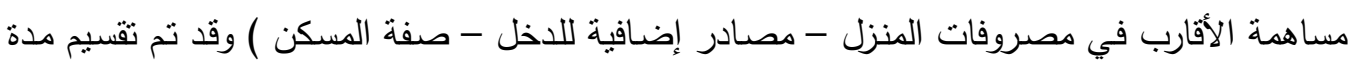

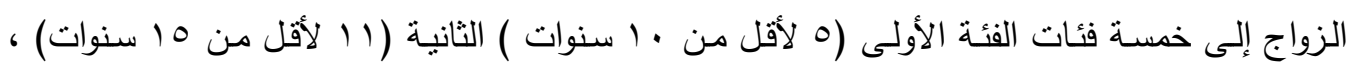

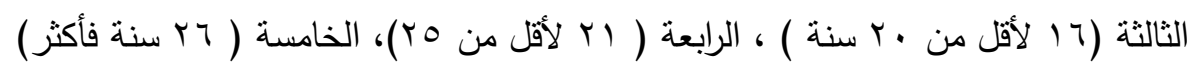




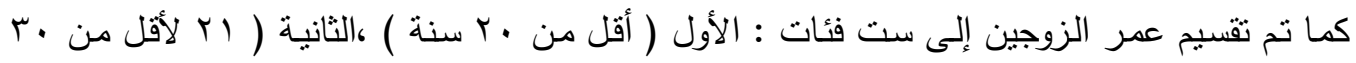

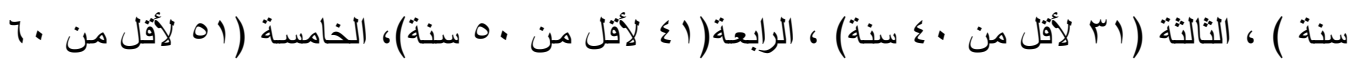

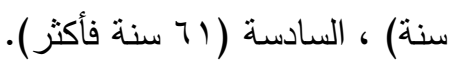

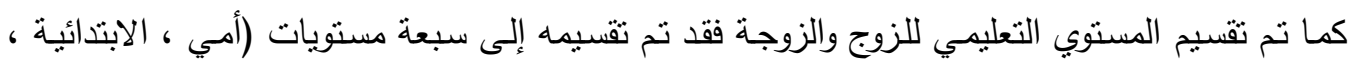

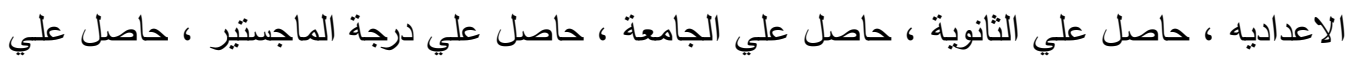

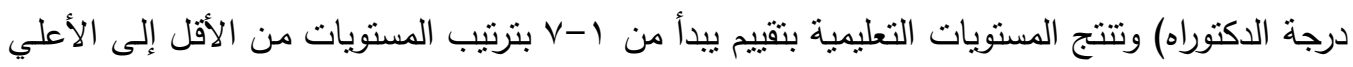

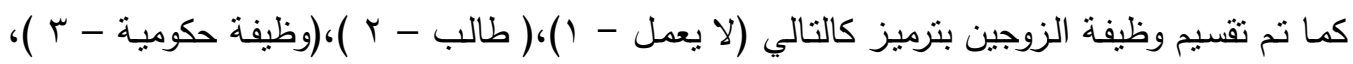
(وظيفية في قطاع خاص - ـ ؟)، (أعمال حره - 0 ) )(متقاعد - 7 ) ).

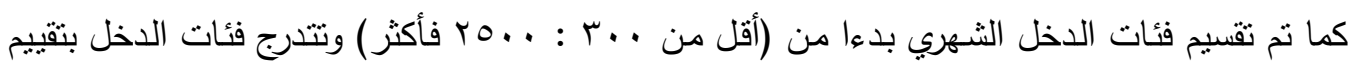

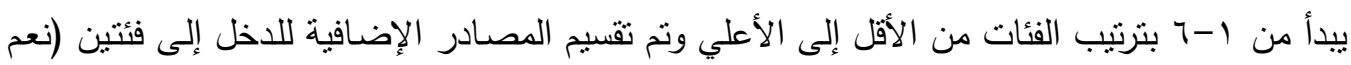

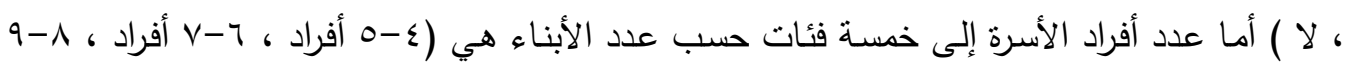

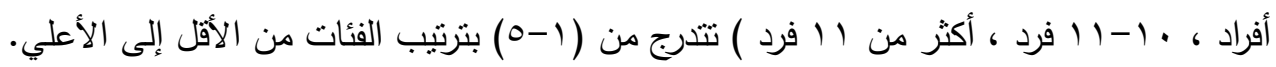

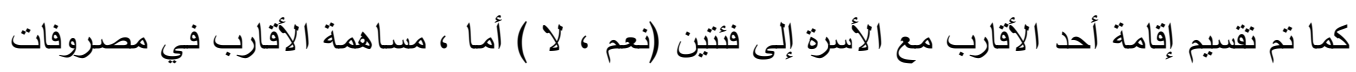

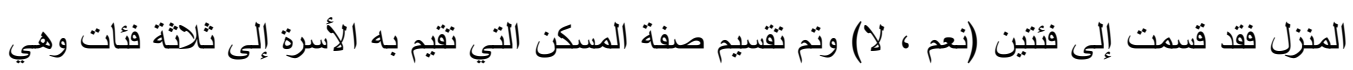

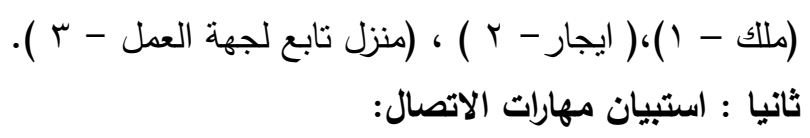

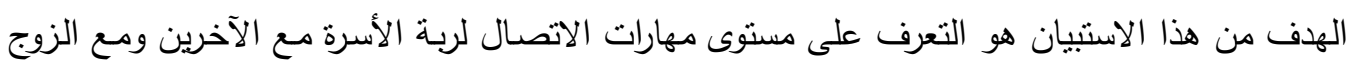

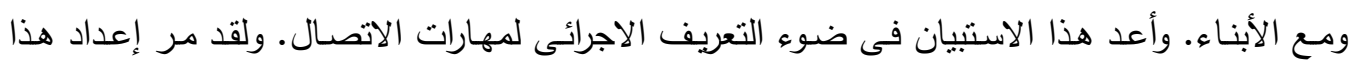

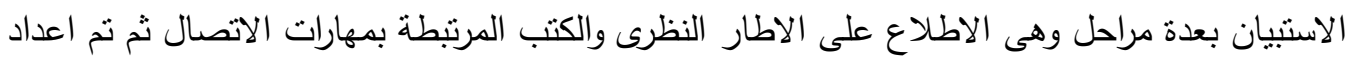

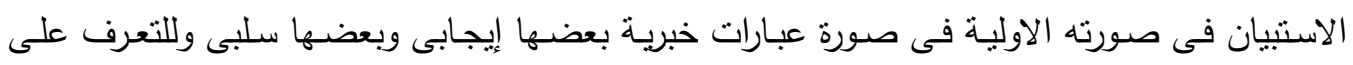
صدق Validity الاستبيان نم عرضه على مجموعة من المتخصصين فى قسم ادارة المنزل والمؤسسات بجامعة المنوفية حيث تم حذف بعض العبارات وتعديل صياغة بعض العبارات وفقا لآراء المحكمين

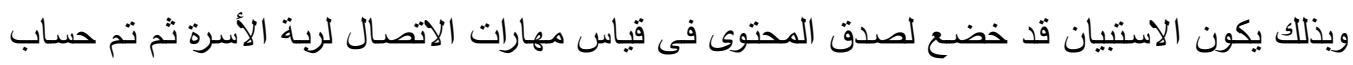

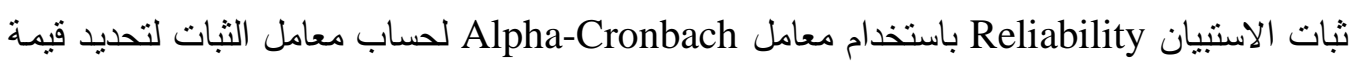

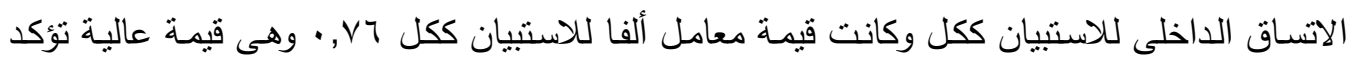
على انساق استبيان مهارات الاتصال. ويتكون استبيان مهارات الاتصال من ثلاث أبعاد هم: 
الاتصـال مـع الأخرين: احتوي هذا البعد علي (rآ) عبارة تدور حول مهارات اتصـال ربـة الأسرة مـع

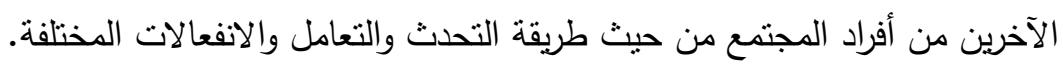

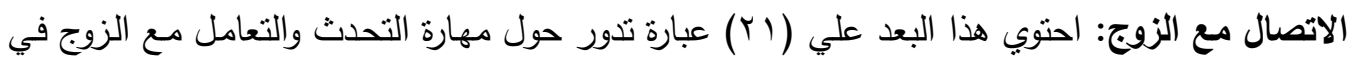

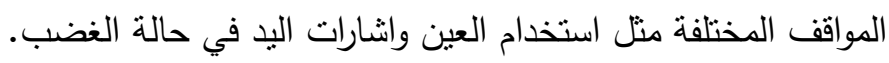

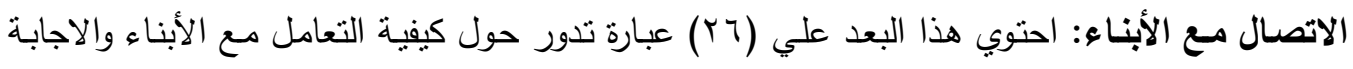
على استفساراتهم وتوضيح الخطأ والصواب بطريقة فعالة والتفاعل معهم خلال مراحل حياتهم المختلفة.

ثالثا :استبيان قدرة ربة الأسرة على مواجهة الضغوط الأسرية:

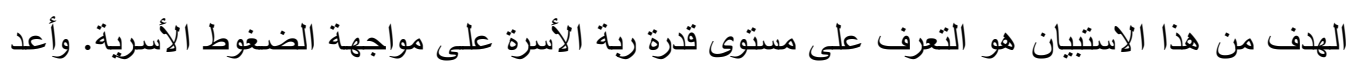
هذا الاستيان فى ضوء التعريف الاجرائى للضغوط الأسرية. ولقد مر إعداد هذا الاستبيان بعدة مراحل

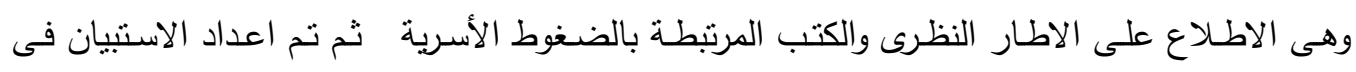

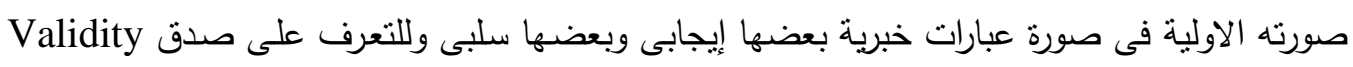

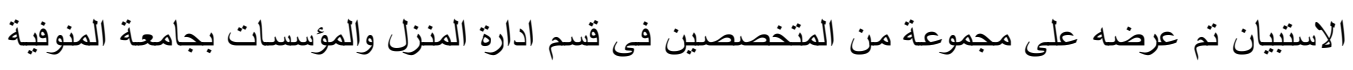

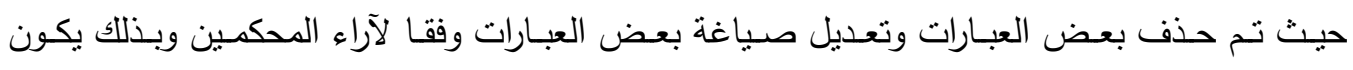

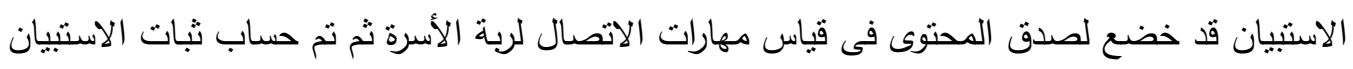

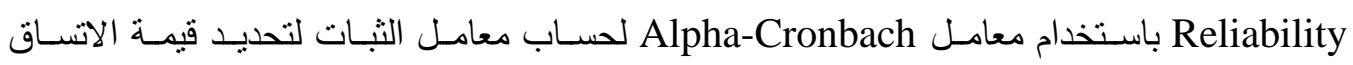

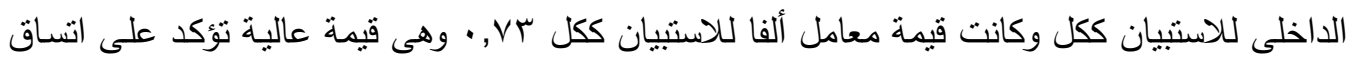
استبيان قدرة ربة الأسرة على مواجهة الضغوط الأسرية.

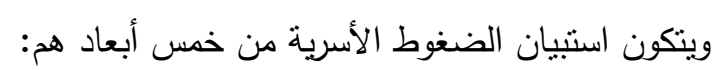

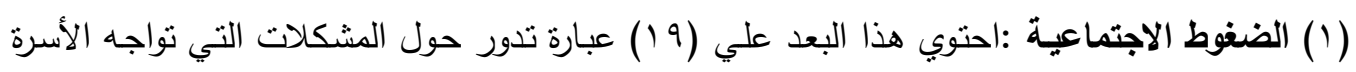

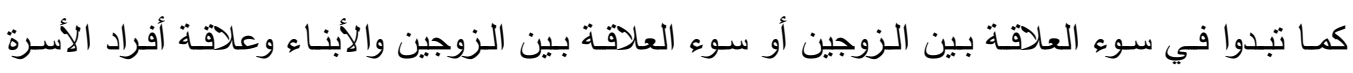
بالمجنمع الخارجي. (Y) الضغوط الاقتصادية :احتوي هذا البعد علي (Yr) عبارة تدور حول مشاكل الأسرة الاقتصادية مثل الدخل المحدود. (r) الضغوط النفسية : احتوي هذا البعد علي (•r) عبارة تدور حول الضغوط النفسية التي تتعرض لها

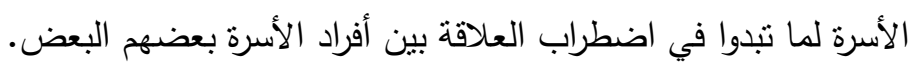

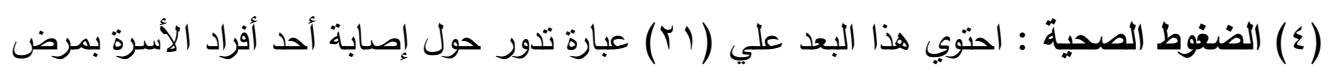
مزمن أو العقم أو غيره. 
(0) الضغوط الاينية والأخلاقيه : احتوي هذا البعد علي (•r) عبارة تدور حول سوء الأخلاق والتربية الدينية. خامسا :صدق الاتساق الداخلي للأدوات :

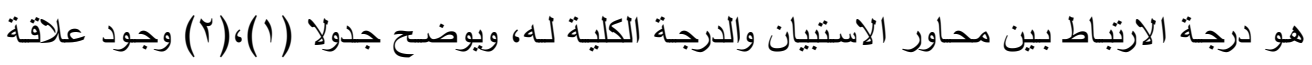

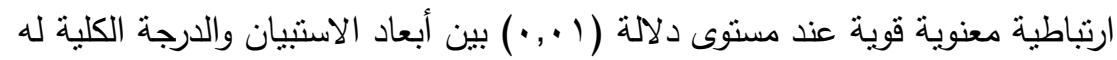

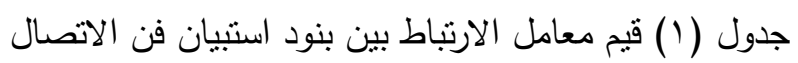

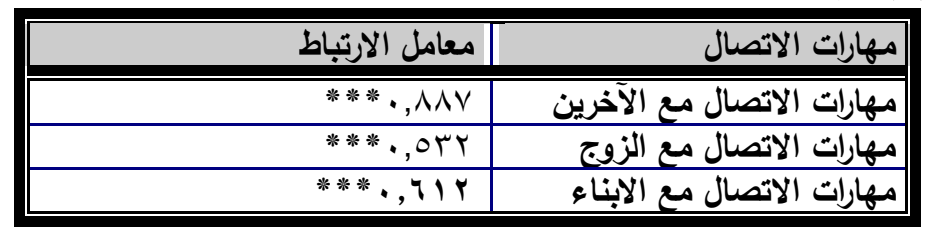

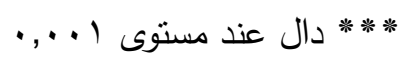
- يتضح من جدول ( ) أن قيم معامل الارتباط عالية وذلك يدل على الاتساق الداخلي للاسنتيان.

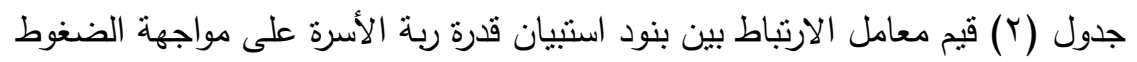

\begin{tabular}{|c|c|}
\hline معامل الارتباط & الضغوط الأسرية \\
\hline ***., \{\rceil$\wedge$ & ضغوط اجتماعية \\
\hline ***., $79 \varepsilon$ & ضغوط اقتصادية \\
\hline ***, & ضغوط نفسية \\
\hline$* * *, \vee \vee \vee \varepsilon$ & ضغوط صحية \\
\hline$* * *, V Y \leq$ & ضغوط دينية وأخلاقية \\
\hline
\end{tabular}

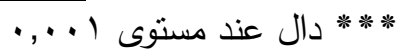

- يتضح من جدول (r) أن قيم معامل الارتباط عالية وذلك يدل على الاتساق الداخلي للاسنتيان.

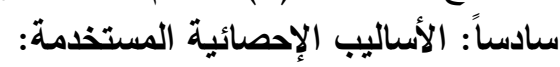

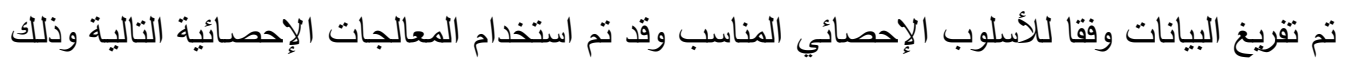

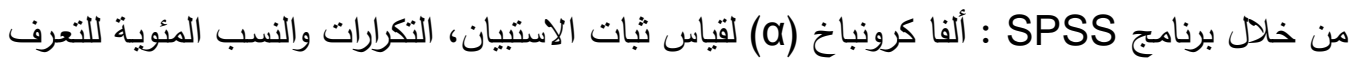

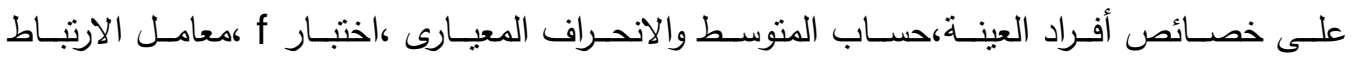
.correlation

\section{نتائج الاراسة الميدانية}

\section{أولا:وصف عينة الدراسة}

فيما يلي وصف لعينة البحث والتي تمثلت في ^ا إ ربة أسرة واللاتي تم اختبارهن بطريقة صدفية من محافظة المنوفية. جدول (r) النوزيع النسبي لعينة الدراسة تبعاً للخصائص الإجتماعية والإقتصادية الزوجة الزوج عمر التسبة المئوية الإدد مدة الزواج 


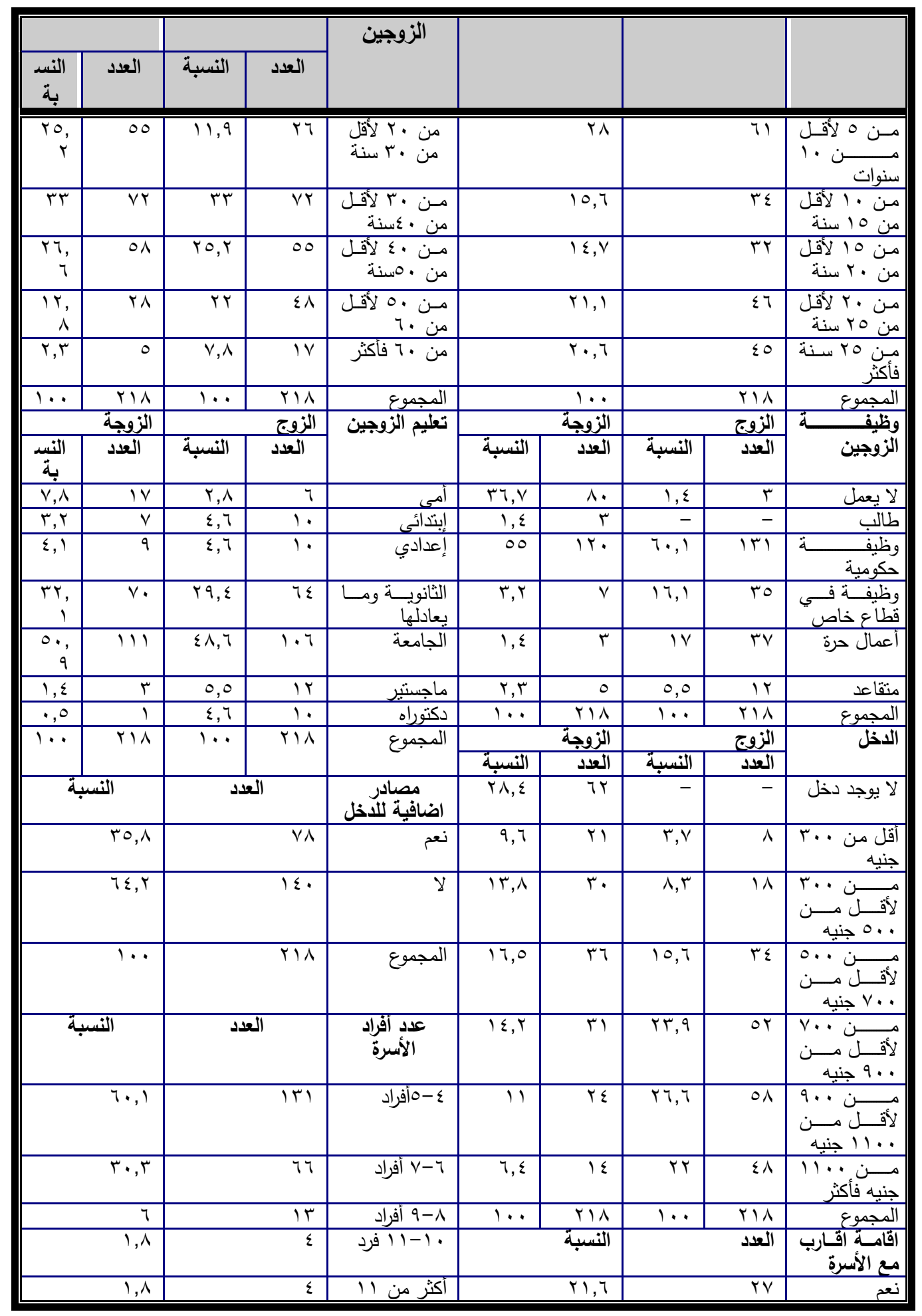




\begin{tabular}{|c|c|c|c|c|c|}
\hline $1 \cdots$ & YוA & المجموع & 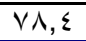 & $1 V 1$ & $\bar{y}$ \\
\hline النسبة & العدد & صفة مسكن & $1 \ldots$ & YIA & المجموع \\
\hline$\wedge \wedge, 1$ & $19 r$ & ملك & النسبةة & العدد & 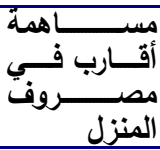 \\
\hline 11 & $r \varepsilon$ & إيجار & $1 \leq, r$ & M & نعم \\
\hline$\cdot, 9$ & $r$ & لجـهــزل تلعملـابع & $\wedge 0, \wedge$ & $1 \wedge V$ & $y$ \\
\hline $1 \ldots$ & YIN & المجموع & $1 \ldots$ & YIA & المجموع \\
\hline
\end{tabular}

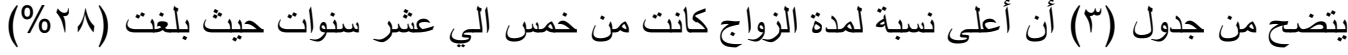

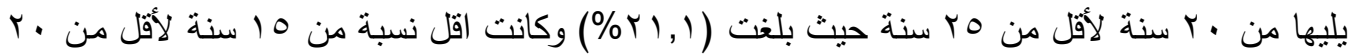

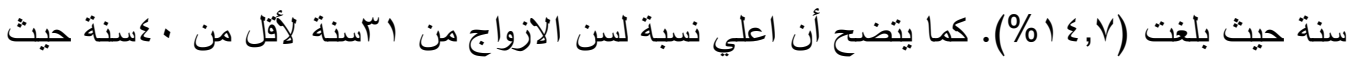

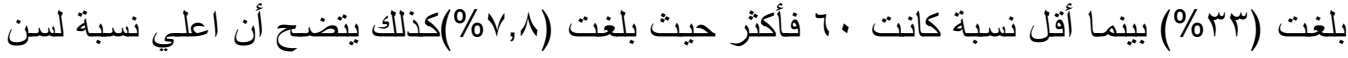

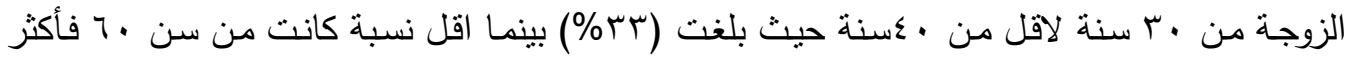

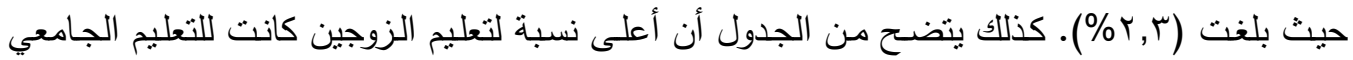

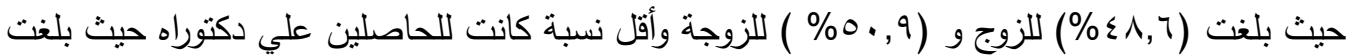

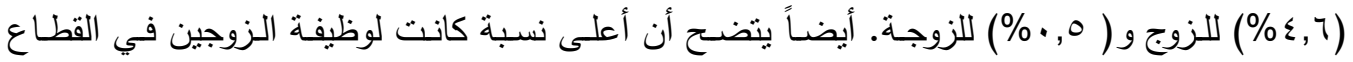

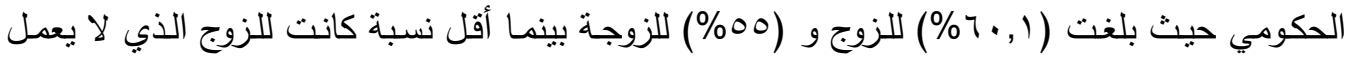

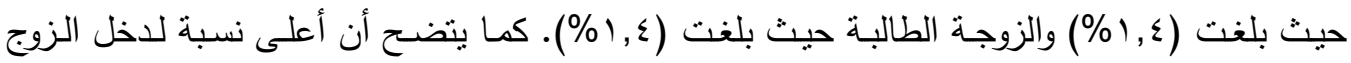

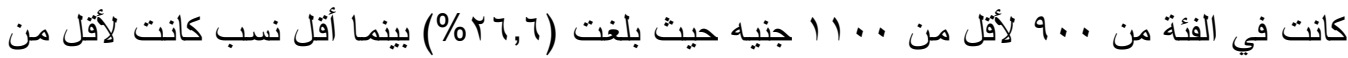

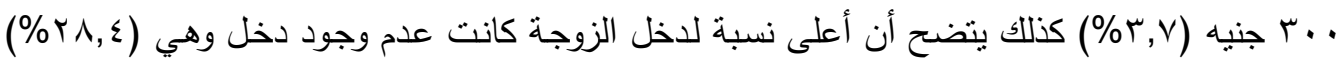

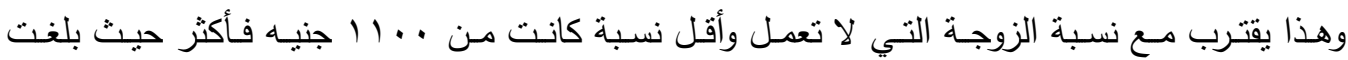

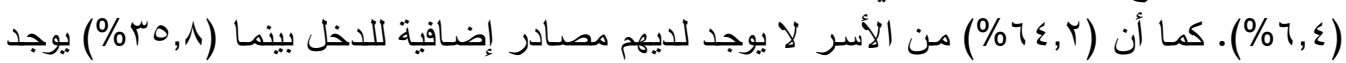

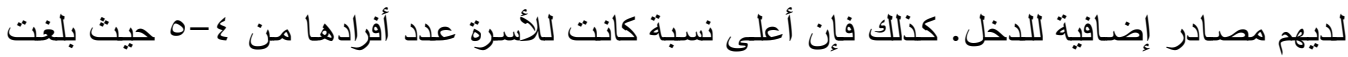

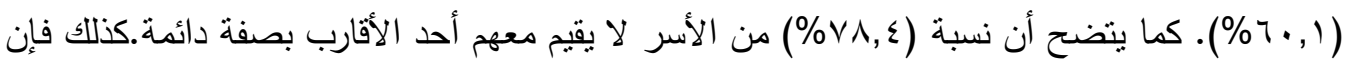

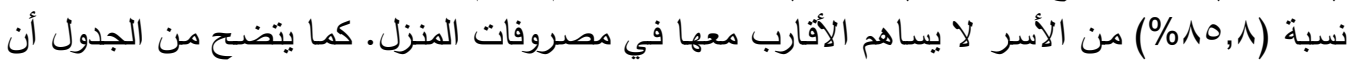

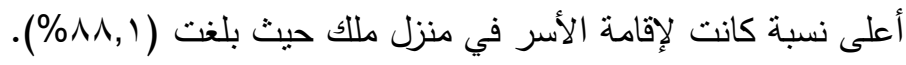

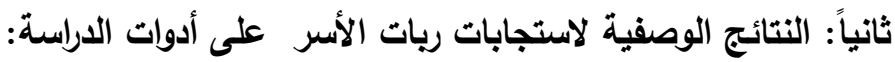
- وصف استجابات عينة البحث على استبيان مهارات الاتصال: أ)(البعد الأول مهارة الاتصال مع الأخرين جدول (؟) التوزيع النسبي لعينة الدراسة تبعاً لاستجاباتهم علي استبيان مهارات الاتصال مع الآخرين الآنين

\begin{tabular}{|c|c|c|c|c|c|c|c|}
\hline \multicolumn{2}{|c|}{$\bar{y}$} & \multicolumn{2}{|c|}{ الحيانا } & \multicolumn{2}{|c|}{ نَع } & \multirow{2}{*}{ العبارات } & \multirow[t]{2}{*}{ م } \\
\hline النسبة & العدد & الننبية & العدد & النسبة & العدد & & \\
\hline 0 & $\pi$ & $T T, z$ & TV & $\lambda T, T$ & 11. & 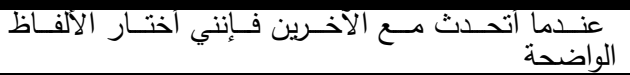 & $T$ \\
\hline $7, \varepsilon$ & $1 \varepsilon$ & $r \wedge, 1$ & $\lambda T$ & 00,0 & TIT & أستطيع تلخيص أفكاري بكلمات بسيطة & $T$ \\
\hline
\end{tabular}




\begin{tabular}{|c|c|c|c|c|c|c|c|}
\hline \multicolumn{2}{|c|}{ ע } & \multicolumn{2}{|c|}{ إحيانًا } & \multicolumn{2}{|c|}{ تَعْم } & \multirow[t]{2}{*}{ العبارات } & \\
\hline النسبة & العدد & النسبة & العدد & النسبة & 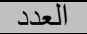 & & \\
\hline$\nabla, T$ & $T 7$ & $T V, 1$ & 09 & 70,7 & $T E T$ & 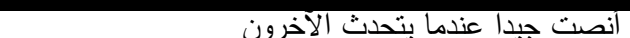 & \\
\hline$\nabla, \Lambda$ & TV & $\varepsilon T, 1$ & 9ह & $\varepsilon 9,1$ & $1 \cdot \mathrm{V}$ & أكتز من وسبلة للتعبير عن ارائي & $\xi$ \\
\hline$\Lambda, V$ & 19 & $19, \varepsilon$ & Tร & 91,9 & 110 & احوال فهم تعبيرات وجه من بتحدث إلى & o \\
\hline 77,1 & OV & 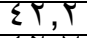 & 97 & $T, \mathrm{~V}$ & 79 & ارفع صوتى بدرجة تجعل الاخرين يستمعون لى جيدا & \\
\hline TA, 9 & $\pi$ & $\varepsilon T, V$ & 95 & $T \Lambda, \xi$ & $\pi$ & إنشارات البّ للتعبير عن أفكاري & \\
\hline 10,1 & TT & $\varepsilon \cdot, \varepsilon$ & AN & $\varepsilon \varepsilon, 0$ & $9 \mathrm{~V}$ & لا اتحدث في انثاء حديث اب شُخص معى. & $\Lambda$ \\
\hline$\varepsilon, 1$ & 9 & $7 \cdot, 7$ & TIT & $10, \Gamma$ & VV & اتضايق من مقاطعة الاخربن لى عندما اتحدث & \\
\hline $7, \xi$ & TE & 0,0 & $\pi \cdot$ & $\varepsilon \Gamma, 1$ & qह & اضبط مشاعري عندما بستشتشني الاخرين & \\
\hline$\pi$ & TE & 01,1 & TV & $T \cdot, V$ & TV & استطيع ان اتحكم في انفعالاتي عند الغضب & $\pi$ \\
\hline 7,9 & 10 & $\xi \cdot, \lambda$ & 199 & $0, T$ & $\pi \varepsilon$ & افهُ مشاعر الاخرين نحوي من خلال ملاحظة طريقة & $T$ \\
\hline$T, T$ & 0 & $T V, T$ & AT & $7 \cdot, 1$ & $T 1$ & جيدا عندما يتحدث الاخرو & $T$ \\
\hline $\mathrm{V}, \mathrm{r}$ & 17 & $\varepsilon \Gamma, 1$ & $9 \varepsilon$ & $\varepsilon 9,0$ & $1 \cdot 1$ & أن افهر الاخرين من خلال نظرات عبونه & $1 \varepsilon$ \\
\hline$T, \Lambda$ & 7 & $\xi 1, V$ & 9) & 00,0 & Tा & التتعبير عن مشاعري من خلال نظراتى للاخرين & 10 \\
\hline T, & T & $O T, \mathrm{~V}$ & TV & ह0 & 91 & م إقناع الاخرين بوجهة نظري & 7 \\
\hline$\cdot, 9$ & t & $\varepsilon \Gamma, q$ & 90 & 00,0 & TY & أثجع الاخرين علي الحديث باسلوب بسيط & \\
\hline$\nabla, \Gamma$ & 17 & $T V, T$ & AT & 00 & Tr. & يمكنني ان اعبر عن نفسي بعبارات محددة & 1人 \\
\hline 17,0 & Ti & $\xi \cdot, \Lambda$ & 199 & $E T, V$ & 91 & الآخـتطيع التحـدث في نفس الوقت الـذي يتحـدث فيـهـ & \\
\hline 17,1 & To & $T, 1$ & $\varepsilon 7$ & $\pi, \Lambda$ & TTV & ليس من الضروري ملاحظة تغيرات وجه الاخرين & r. \\
\hline $17, r$ & Vq & TA & 7) & To,A & $\nabla \Lambda$ & لا استطيع التعبير عن نفسي من خلال حركات جسمى & Tा \\
\hline $7 \cdot, 7$ & TT & TA, & Tr & $\pi$ & TE & اتوقف عن الحديث عندما الاحظظ عدم تجاوب الاخرين & TT \\
\hline$O Y, \Lambda$ & 110 & $T \wedge, q$ & 75 & $T \wedge, \Gamma$ & $\xi \cdot$ & لت عـن مناقتـــة أفراد الاسـرة في الامـور التـي لا & TT \\
\hline$\varepsilon, 1$ & 9 & TT & VT & $\pi, \Lambda$ & ITV & عندما اتحدث مع أفراد اسرتي لا أحاول جرح مشاعرهم & Tร \\
\hline TO, V & 09 & $0 \wedge, V$ & TIR & 10,7 & TE & أعاني من صعوبة في نوصيل أفكاري للاخرين بطريقة & To \\
\hline 9,7 & T) & $71, r$ & $1 \leqslant 9$ & TY & $\varepsilon \wedge$ & نحوهالْ لعدم قدرتي علي جعل الاخخرين يفهمون مشـاعري & 7 \\
\hline TV,T & $\lambda 1$ & Tq,, & $\Lambda \tau$ & $T T, \varepsilon$ & 01 & اشُعر بالخجل الثديد مع عند التحدث مع الغرباء & V \\
\hline$T T, \varepsilon$ & 01 & $0 \xi, 1$ & $\pi / 1$ & $T, 0$ & ह9 & اجد صعوبة في التحدث مع أفراد من الجنس الاخر & TA \\
\hline $19, \mathrm{~V}$ & हT & T4,V & A. & हा, & 90 & أعبر عن ارائي باقلّ عدد من الكلمات & 19 \\
\hline$T, 1$ & OV & $\xi \xi, 0$ & $9 \mathrm{~V}$ & $19, \xi$ & Tร & 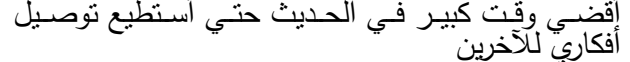 & T. \\
\hline 7 & $T$ & $0 V, 1$ & 110 & 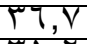 & $\Lambda \cdot$ & عندما اتحدث اختار الالفاظ بدقة & 11 \\
\hline$T \cdot, V$ & TV & $T \Lambda, 1$ & $\lambda T$ & $T, Y$ & Th & أجذر صعوبة لتوصيل افكاري بكلمات بسبطة إلي من هم & TT \\
\hline$T \pi, 9$ & OY & हा, & 90 & TT, T & VI & أكبر منيع توصنال افكاري بطريقة غير لفظية إلي من هم & TT \\
\hline
\end{tabular}

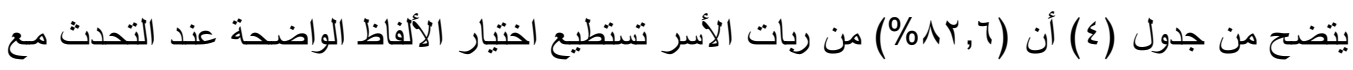
الآخرين وإن (9, (1\%\%) من ربات الأسر تحاول فهم تعبيرات وجه من يتحدث إليها كذلك أكدت (00\%)

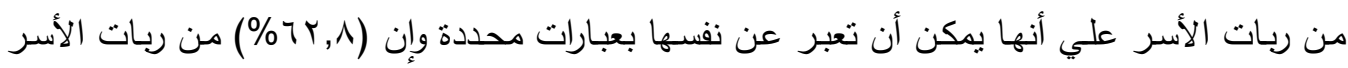

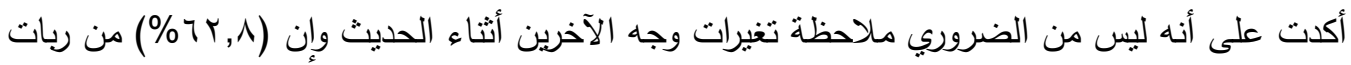
الأسر تحرص على عدم جرح مشاعر أفراد الأسرة عند التحدث معهم. ب)(البعد الثانى مهارة الاتصال مع الزوج 
جدول (0) التوزيع النسبي لعينة الدراسة تبعاً لاستجاباتهم علي استبيان مهارات الاتصال مع الزوج

\begin{tabular}{|c|c|c|c|c|c|c|c|}
\hline \multicolumn{2}{|c|}{$\bar{\gamma}$} & \multicolumn{2}{|c|}{ احيانا } & \multicolumn{2}{|c|}{ نَعم } & \multirow[t]{2}{*}{ 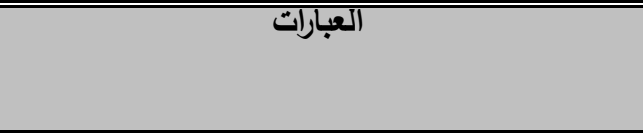 } & \multirow[t]{2}{*}{ r } \\
\hline 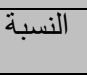 & 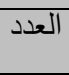 & 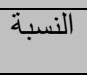 & 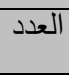 & 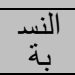 & 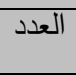 & & \\
\hline $1 \cdot, 1$ & Tr & rq & 10 & $0 ., 9$ & 111 & قد زجد صعوبة في اختيار الالفاظ المناسبة عند الحديث & $T$ \\
\hline$\Lambda, \vee$ & 19 & $\sum 1, \Gamma$ & $9 \cdot$ & 0. & 1.9 & مذلّك الصعب علي معرفة إن كان زوجي حزين عندما يكون & $T$ \\
\hline$T, Y$ & 71 & 01,1 & $11 \pi$ & TV & TV & 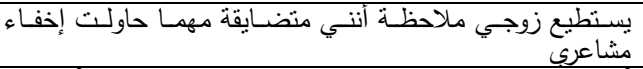 & $T$ \\
\hline 0,0 & $T r$ & $r, 1$ & $\leqslant 7$ & $V \Psi, \Sigma$ & 17. & أستمتع بوجودي في الحفلات والرحلات مع زوجي وابنائي & $\varepsilon$ \\
\hline 0 & 11 & $r \cdot, T$ & $\leqslant 0$ & $V \varepsilon, \Gamma$ & 174 & اعرف زوجي من خلال تعبيرات وجها & 0 \\
\hline$T \xi, T$ & or & $1 \cdot, 1$ & TY & 70,7 & $T \leqslant r$ & من الصعب ان انظر في وجه زوجي عندما اتحدث معه & 7 \\
\hline$\cdot, 9$ & T & rq, r & $\mathrm{Vq}$ & $T, \Lambda$ & THV & اعرف مشاعر زوجي من عينيه & $\mathrm{V}$ \\
\hline$\cdot, 9$ & T & 07 & TYY & TYY & $9 \leq$ & اهتم بمعرفةٌ ما يجذب انتباه زوجي & $\Lambda$ \\
\hline$r \wedge, q$ & $7 \pi$ & $\leqslant 0,9$ & $1 \ldots$ & $T O, Y$ & 00 & زشوأَعزي لـبس مـاهرا في ضـبط انفعالاتـه او الـتحكم في & 9 \\
\hline$\xi, 7$ & 1. & 01,1 & $\pi \pi$ & $\varepsilon \mu, \tau$ & 90 & بسود جو ودي بيني وبين زوجي اثناء التحدث & $1 \cdot$ \\
\hline IY, & TV & $\leqslant \varepsilon$ & 97 & $\varepsilon r, \uparrow$ & 90 & يشجعني زوجي علي طرح أفكاري جديدة للتغيير في حياتتا & 11 \\
\hline $0 \leqslant, 7$ & 119 & $T r$ & $V Y$ & TY, & TV & نستخدم انا وزوجي الورقة والقلم لتوضيح بعض الامور & Tr \\
\hline$\Lambda, \mathrm{V}$ & 19 & $\varepsilon \Lambda, Y$ & 1.0 & $\varepsilon r, 1$ & $9 \varepsilon$ & حينما اتثاجر مع زوجي احرك يداي بعصبية شديدة & $\pi$ \\
\hline YO,V & 07 & $\varepsilon \vee, Y$ & $1 \cdot r$ & $r V, 1$ & 09 & 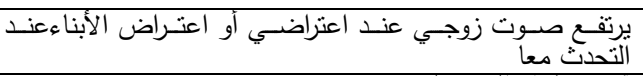 & Tร \\
\hline 0,0 & IT & $0 \leqslant, 1$ & 111 & $\varepsilon \cdot, \varepsilon$ & $\Lambda \Lambda$ & اهتم كثيرا بالتزين لزوجي & 10 \\
\hline Y^ & 71 & r & VY & rq & 10 & يهتم زوجي بالتزين امامي & 17 \\
\hline$r, r$ & V & IV & re & $\vee \vee, \wedge$ & $1 V \varepsilon$ & اهتم بنظافة ومظهر ابنائي في المنزل & IV \\
\hline$\Gamma \wedge, 0$ & $\Lambda \varepsilon$ & r廿,V & A. & $T \leqslant, \Lambda$ & $0 \xi$ & يحرص زوجي علي الخروج للنتزه معنا علي فترات منتظمة & 11 \\
\hline 0,0 & ir & 0 . & 1.9 & $\varepsilon \varepsilon, 0$ & $9 V$ & يغلق زوجي الابواب بعنف أثناء انفعاله & 19 \\
\hline$r \cdot, r$ & $\varepsilon \varepsilon$ & Or, r & $11 \varepsilon$ & $T V, O$ & 7. & يرتفع صوت الابناء أثناء الثجار & T. \\
\hline$I_{1}, \Lambda$ & YA & $\leqslant 9,0$ & $1 \cdot 1$ & $r V, T$ & AT & يحرك ابني يداه بعصبية اثثاء التحدث معي أو مع والده & YI \\
\hline
\end{tabular}

يتضـح من جدول (0) أن نصف ربـات الأسـر عينـة الدراسـة (9 ، .0\%) تجدن صـوبات في اختيـار الألفاظ المناسبة عند الحديث مع زوجها، كذلك أكدت (9, .0\%) من ربات الأسر علي أنها تجد صعوبة في اختيار الألفاظ المناسبة عند الحديث مع زوجها،كما أن ( •0\%) أكدت على أنه من الصعب عليها

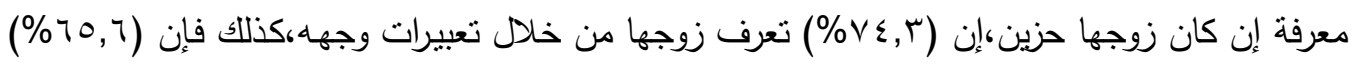

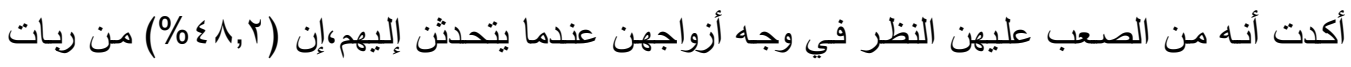
الأسر أحياناً تحرك بداها بعصبية شديدة حينما تتشاجر مع زوجها. ج)البعد الثالث مهارة الاتصال مـع الأبناء 
جدول (T) التوزيع النسبي لعينة الدراسة تبعاً لاستجاباتهم على استبيان مهارات الاتصال مع الابناء

\begin{tabular}{|c|c|c|c|c|c|c|c|}
\hline \multicolumn{2}{|c|}{$\bar{y}$} & \multicolumn{2}{|c|}{ الحيانا } & \multicolumn{2}{|c|}{ نَع } & \multirow{2}{*}{ 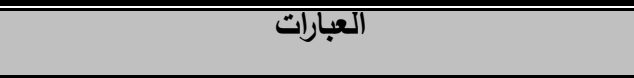 } & \multirow[t]{2}{*}{ p } \\
\hline النسبيه & العدد & ألنسبه & العدد & ألنسبه & العدد & & \\
\hline$\Lambda, r$ & 11 & YT, & 01 & $7 \Lambda, r$ & $1 \leq 9$ & & $\frac{1}{1}$ \\
\hline IV & TV & $T V, \xi$ & Th & 70,7 & $1 \leqslant \Gamma$ & يتيّعد & $Y$ \\
\hline $19, r$ & $\varepsilon T$ & $\mathrm{~V} \theta, \Lambda$ & 189 & PY, 9 & 0. & الاستماع إلـي & $\Gamma$ \\
\hline Yo,V & 07 & 01,1 & $11 \%$ & YY,O & $\$ 9$ & عن افكارى جيدا & $\xi$ \\
\hline $0 \Lambda, \Gamma$ & TIV & rq,V & $\Lambda$. & 0 & $\pi$ & نَ شُخص في نَس & $\theta$ \\
\hline$\varepsilon, 1$ & 9 & 19,1 & 70 & 79,1 & $1 \leqslant \leqslant$ & اقتشـــه محـدلد اسـتطيع & 7 \\
\hline$T \leqslant, \Lambda$ & $0 \leqslant$ & $r \wedge, 1$ & $\Lambda \Gamma$ & rV,Y & $\Lambda 1$ & عدة تقسيرات. & $\mathrm{V}$ \\
\hline 7 & Tr & 29,0 & 1.1 & $\varepsilon \varepsilon, 0$ & 9V & اجد سهوله & $\Lambda$ \\
\hline 10,1 & Tr & $V \theta, r$ & 1ro & TV,O & 7. & ليجه لسرعه & 9 \\
\hline$T Y, \Lambda$ & Yर & $\xi \cdot, \Lambda$ & 19 & $\varepsilon 7, r$ & $1 \cdot 1$ & $=1$ & $1 \cdot$ \\
\hline PT, & 01 & iv & TV & 09,9 & 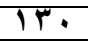 & j) & $\pi$ \\
\hline YY,O & $\leqslant 9$ & $T V, \varepsilon$ & Ti & $7 \cdot, 1$ & $1 \pi 1$ & القاء الاسئلة & Tr \\
\hline $1 \cdot, 7$ & YT & $1 \leq, Y$ & T & $V \theta, Y$ & $17 \varepsilon$ & عن افكـارهم بحريــا & ir \\
\hline rY & $\leqslant \wedge$ & $\varepsilon V, Y$ & $1 \cdot r$ & $r \cdot, V$ & TV & ب للطفل. & $1 \leqslant$ \\
\hline$\Lambda, V$ & 19 & $1 V, \varepsilon$ & $\mathrm{rN}$ & VT, & 171 & المختالفة & 10 \\
\hline- & - & 9,7 & YI & $9 \cdot, 5$ & $19 V$ & آز بها & 17 \\
\hline $9, r$ & r. & 11 & Y\& & $\vee q, \Lambda$ & IV $\varepsilon$ & إدراك ما يقوله الطفل. & IV \\
\hline 11 & Y & 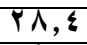 & $7 Y$ & $7 \cdot, 7$ & ITr & 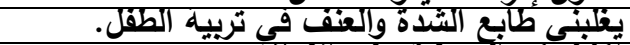 & 11 \\
\hline$T r, \Lambda$ & Th & 29,0 & 1.1 & rV, 7 & AT & أنفعالآتّ & 19 \\
\hline$\varepsilon, 1$ & 9 & Tर & 71 & $7 V, 9$ & $1 \leq 1$ & عنـــــرح السـوأل علـي & r. \\
\hline$\nabla, r$ & 17 & rq,Y & $v q$ & $07, \xi$ & TrT & عيـون ووجـه ابنـائي أنـــاء & YT \\
\hline 10,7 & $r \varepsilon$ & 81,7 & 107 & $I Y, \Lambda$ & rA & 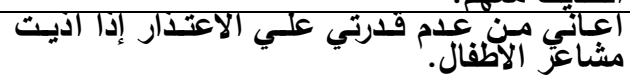 & re \\
\hline$\sum Y, V$ & $9 \pi$ & P , द & $7 \varepsilon$ & in & $\pi$ & اعتبر صمت الّطقل احد أنواع الإجابه. & Tr \\
\hline$\varepsilon, 7$ & $1 \cdot$ & 7,9 & 10 & $\Lambda \Lambda, 0$ & 149 & اركز على ان يسمعني الطفل عند توجيها. & $Y \leqslant$ \\
\hline$r, Y$ & $\mathrm{~V}$ & $1 V, \varepsilon$ & $\Gamma \wedge$ & Vq, \& & IVT & ك ئ وملا & ro \\
\hline $1 T, \Lambda$ & $r$ & $\leqslant 0$ & 91 & $\leqslant 1, r$ & 9. & ردي على ابنائَى يلائم ويراعى انْعَالاتههم. & rq \\
\hline
\end{tabular}

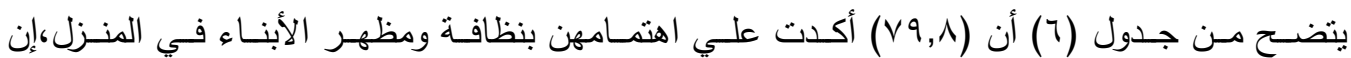

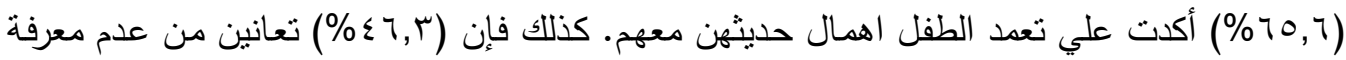
نمط شخصية أطفالهن،إن (1, • ؟\%) أكدت علي أن العصبية هي السمة السائدة اثثاء القاء الاسئلة

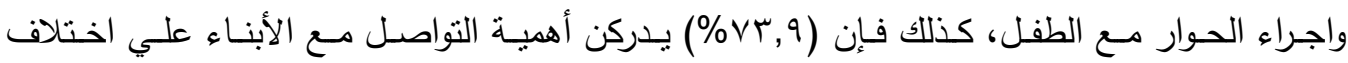

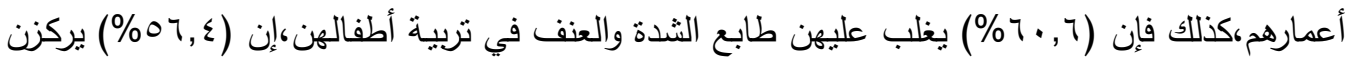

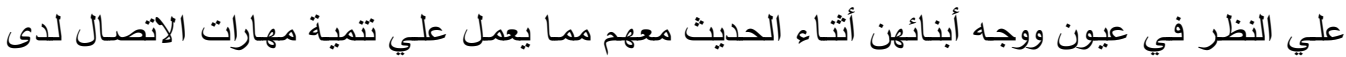

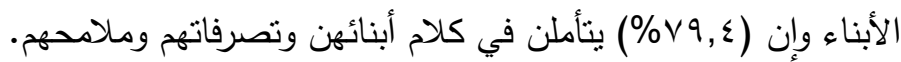
د)|ستجابات ريات الأسر على استبيان مهارات الاتصال الأسري 
جدول (V) التوزيع النسبي لعينة الدراسة تبعا لمستوي مهارات الاتصال الأسري.

\begin{tabular}{|c|c|c|}
\hline النسبة المئويسة & العـد & مستوي مهارات الاتصال الأسري \\
\hline $1 \varepsilon, Y$ & m & 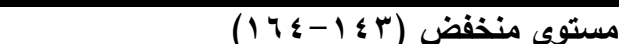 \\
\hline$\varepsilon \wedge, 7$ & 1.7 & مستوي متوسط (0 ا I - I I) \\
\hline$r V, r$ & $\Lambda 1$ & 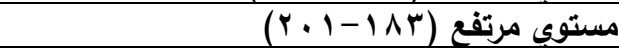 \\
\hline $1 \ldots$ & YIN & المجموع \\
\hline
\end{tabular}

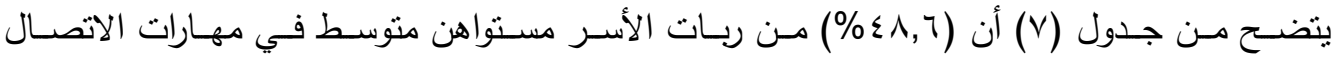

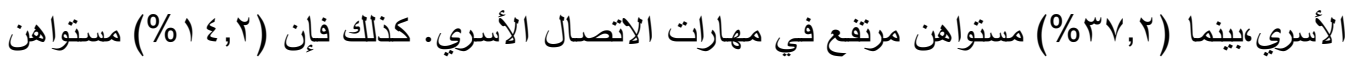
منخفض في مهارات الاتصال الأسري.

- وصف استجابات عينة البحث على استبيان قرة ربة الأسرة على مواجهة الضغوط :

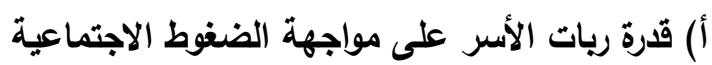
جدول (^) التوزيع النسبي لعينة الدراسة تبعاً لاستجاباتهم علي استبيان قدرة ربات الأسية الأسر على مواجهة الضغوط الاجتماعية

\begin{tabular}{|c|c|c|c|c|c|c|c|}
\hline \multicolumn{2}{|c|}{$\overline{\mathrm{y}}$} & \multicolumn{2}{|c|}{ احيانا } & \multicolumn{2}{|c|}{ تُعد } & \multirow[t]{2}{*}{ العبارات } & \multirow[t]{2}{*}{ م } \\
\hline النسبة & 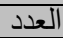 & النسبة & العدد & النسبة & العدد & & \\
\hline$\pi$ & TE & $\sum 0$ & 91 & $\varepsilon \varepsilon$ & 97 & 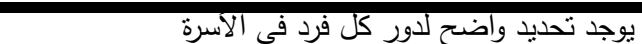 & \\
\hline 10,7 & TE & 74,1 & $1 \leq \varepsilon$ & $1 \wedge, T$ & $\varepsilon \cdot$ & 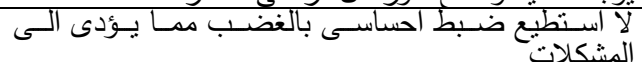 & T \\
\hline$\Lambda, V$ & 19 & $\varepsilon \Lambda, Y$ & 1.0 & $\varepsilon \Gamma, 1$ & $9 \varepsilon$ & يوجد وقت كافي للتناقش مع ابنائى & T \\
\hline $1 \Lambda, r$ & $\varepsilon \cdot$ & $\varepsilon 9,0$ & $1 \cdot 1$ & $T, 1$ & $\nabla \cdot$ & من ضيق الوقت لتلبية احتباجات ز & $\xi$ \\
\hline$\pi$ & TE & TE,q 9 & VT & $0 \xi, 1$ & $\pi / 1$ & انتابع ابنائي في استخكار دروسهر & 0 \\
\hline$T, T$ & 0 & 17,0 & T9 & 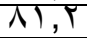 & TVV & احافظظ على ابنائي من الانحراف واختباراصدقاء السوء & 7 \\
\hline TY & हर & 00 & $T r$ & $T, 9$ & 0 . & نختلف انا وزوجي في طريفة تعاملنا مع الابناء & $\mathrm{V}$ \\
\hline$\Lambda, V$ & 19 & rq & 10 & $0 Y, T$ & 11E & اعانى من انعدام الحوار بينى وبين زوجى & $\Lambda$ \\
\hline$V, \Gamma$ & 17 & $\varepsilon \Gamma, 1$ & $9 \varepsilon$ & $\varepsilon 9,0$ & $1 \cdot 1$ & اثشعر بالتقصبر في اداء دورى تجاه الأسرة & 9 \\
\hline 9,1 & T. & TV,T & AI & $0 T, \mathrm{~V}$ & $11 \mathrm{~V}$ & نهتم انأ وزوجي بوضع اهدف محددة وواضحة للاسرة & 1. \\
\hline 7,9 & 10 & 0,9 & $\pi$ & $E T, Y$ & q1 & اطلب مساعدة زوجي واولادى في وقت الضيق & $\pi$ \\
\hline$\varepsilon, 1$ & 9 & $T \cdot, T$ & हร & $\mathrm{V} 0, \mathrm{~V}$ & 170 & احرص على التواصل والتقارب مع افراد اسرتى & $T$ \\
\hline $1 \cdot, 1$ & TT & $\varepsilon 7, \Gamma$ & $1 \cdot 1$ & $\varepsilon \Gamma, T$ & 90 & في حقذ بطريقة ملائمة لاي فرد في الاسـرة عندما اخطىء & $\pi$ \\
\hline$\pi$ & TE & $\varepsilon 0, \xi$ & 99 & $\varepsilon \Gamma, \uparrow$ & 90 & اتسامح على نحو جيد مع اخطاء مع اخطاء افراد اسرتي & TE \\
\hline$T \varepsilon, V$ & TT & $T, T$ & VI & $0 Y, \lambda$ & 110 & التفكير الخلافات بينى وبين زوجى بسبب اختلاف مستوى & 10 \\
\hline$T, T$ & $\mathrm{~V}$ & 79,7 & 1.0 & $\nabla \cdot, T$ & 101 & اهتح بالآشياء التي برغب افراد اسرتى في عملها & 17 \\
\hline$V, \Gamma$ & 17 & $T \varepsilon, \Gamma$ & or & $9 \Lambda, T$ & $1 \leqslant 9$ & خل المشاكل التي نواجه الأسره & IV \\
\hline $7, \xi$ & TE & TE,V & TT & $\nabla \wedge, 9$ & TVY & ارى آن من اهم مسئولِياتى هو الاهتمام بشُئون الأسره & TA \\
\hline$\pi, T$ & T9 & $0 T, \lambda$ & 110 & TT,q & Vद & شئُونى المنزلية تؤُثز على حباتي الأسرية الاجتماعبة & 19 \\
\hline
\end{tabular}

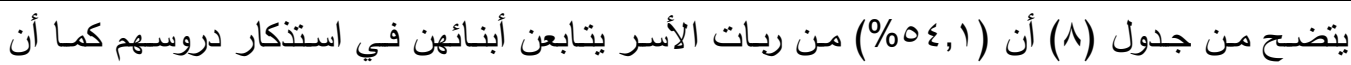
(\%^,〉)

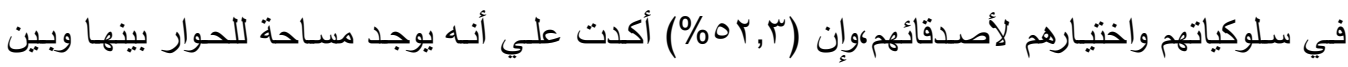
زوجها مما يعمل علي تقليص حجم الضغوط الاجتماعية علي الزوجة وحدها ومشاركة الزوج لها في 


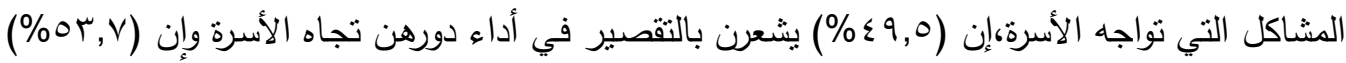

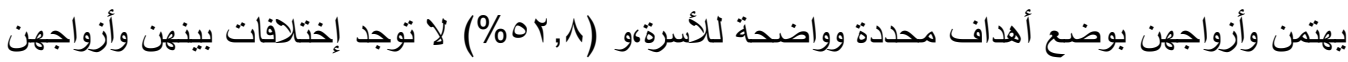

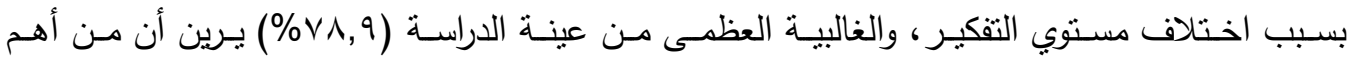
مسئوليتهن هو الاهتمام بشئون الأسرة.

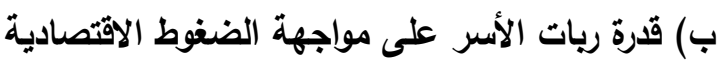

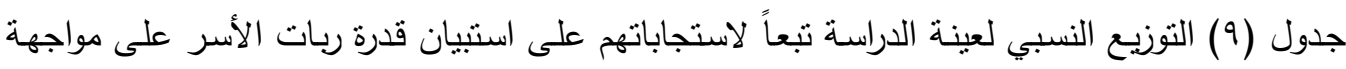
الضغوط الاقتصادية

\begin{tabular}{|c|c|c|c|c|c|c|c|}
\hline \multicolumn{2}{|c|}{$\bar{y}$} & \multicolumn{2}{|c|}{ آحيانا } & \multicolumn{2}{|c|}{ نعم } & \multirow[t]{2}{*}{ 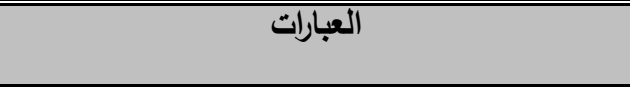 } & \multirow[t]{2}{*}{ ? } \\
\hline النسبة: & العدد & النسبية & العدد & النسببة & |العدد & & \\
\hline 17,0 & ra & $\varepsilon Y, Y$ & 97 & $\varepsilon 1, \Gamma$ & $9 \cdot$ & اقوم بعمل ميزانيه للاسرة فى ظل ارتفاع الاسعار & ) \\
\hline$r V, Y$ & $\wedge 1$ & 07,5 & ITH & $7, \xi$ & $1 \leq$ & تتأثر الميزانيه فى بعض الاوقات من السنه & r \\
\hline TI,V & 79 & $r, v$ & $\Lambda \cdot$ & MI,V & 79 & المظهرية والتفاخر تؤثر على الميزانية & $\mu$ \\
\hline $19, V$ & $\varepsilon r$ & $\varepsilon Y, Y$ & 94 & $r \wedge, l$ & $\Lambda \mu$ & لا اهتم بوضع بند للطوارىء حتى لا تتأثز الميزانيه & $\varepsilon$ \\
\hline$r \cdot, r$ & $\varepsilon \varepsilon$ & $7 V, 9$ & $1 \leqslant \Lambda$ & 11,9 & YY & تتعرض الأسرة لازمات ماليه فى بعض الاوقات & 0 \\
\hline$T, \Lambda$ & TA & $\Gamma \cdot r$ & 77 & 07,9 & TY & الاقوكازيون بشراء احتياجـات زائدة عن حاجـة الأسـره فى فتره & 7 \\
\hline$\varepsilon r, V$ & 90 & $r q, \wedge$ & 70 & Y, 7 & 1० & 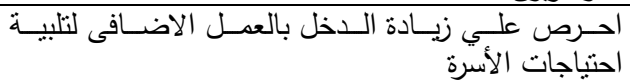 & $\bar{V}$ \\
\hline 11,0 & ro & $r V, r$ & NI & $01, \Sigma$ & $M T$ & ضروريه دخـل الأسـره المحـدود ولا اقوم بشـراء ســع غيـر & $\Lambda$ \\
\hline $1 \leqslant, Y$ & $\Gamma^{\top}$ & rq, $\varepsilon$ & $7 \varepsilon$ & 07,5 & TrT & ألميزانيع قائمـة بالمشتريات قبل الذهاب للشـراء حفاظـا على & 9 \\
\hline$r, r$ & 0 & $r \mu, \varepsilon$ & 01 & $V \varepsilon, r$ & ITr & احدد احتياجات الأسرة الاكثر اهمية ثم الاقل اهميه & $1 \cdot$ \\
\hline IY, & TV & $\varepsilon \varepsilon$ & 97 & $\varepsilon \Gamma, 7$ & 90 & أخصص جزء من الدخل للادخار لمواجهه أى أزمه ماليه & 11 \\
\hline $1 \leqslant, Y$ & $\Gamma_{1}$ & rt & $\varepsilon \wedge$ & $7 r, \Lambda$ & 149 & أتحمل مسؤلية الانفاق على الأسرة بمفردى & Ir \\
\hline$\Lambda, r$ & 11 & rו, & 71 & $7 \cdot, 7$ & ITt & يلبي زوجى جميع احتباجات الأبناء الضروريه & 14 \\
\hline 17,0 & ru & $\varepsilon\urcorner, \Gamma$ & $1 \cdot 1$ & TV,Y & $\Lambda$ & الأحوال حد اعلى لميزانية الثراء ولا أتجاوزها بأى حال من & $1 \leqslant$ \\
\hline$\varepsilon \cdot, \wedge$ & 19 & ro,r & $\overline{V V}$ & rT, & or & اقوم بتجديد ملابس ابنائى القديمة حتى أوفر فى الميزانية & 10 \\
\hline 17,0 & mi & $\varepsilon 1, V$ & 91 & $\varepsilon 1, V$ & 91 & الضتب قائمـة احدد فيها الدخل الكلى للأسرة والاحتياجات & 17 \\
\hline IV & rV & ro,r & $\overline{V V}$ & $\varepsilon \vee, V$ & $1 \cdot \varepsilon$ & اعلم ابنائى قيمة ما لديهم وكيف يتصرفون فى مصروفهم & IV \\
\hline 10,1 & TT & rq & 10 & $\leqslant 0,9$ & $1 \cdots$ & في حالة وجود أزمات مالية ألجأ إلى الاقتراض & 11 \\
\hline$\Lambda, \vee$ & 19 & $0 \cdot, 9$ & 111 & $\varepsilon \cdot, \varepsilon$ & $\wedge \wedge$ & أعانى من الزياده الأسعار مما يؤثر على الميزانيه & 19 \\
\hline $7, \xi$ & $1 \leqslant$ & Y7,7 & 10 & $7 V$ & $1 \leq 7$ & اعانى من كثرة الديون المتراكمه علي الأسرة & r. \\
\hline 0 & 11 & $\varepsilon \varepsilon, 0$ & $9 V$ & $0 \cdot, 0$ & 11. & 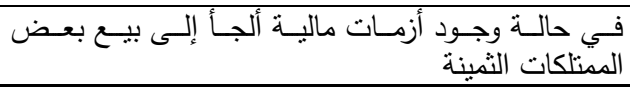 & YI \\
\hline
\end{tabular}


يتضح من جدول (9) إن (9, 7\%\%) يقمن بشراء احتباجات زائدة عن حاجة الأسرة في فترة الأوكازيون

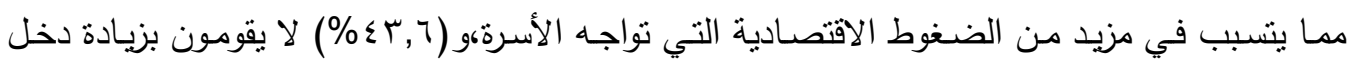

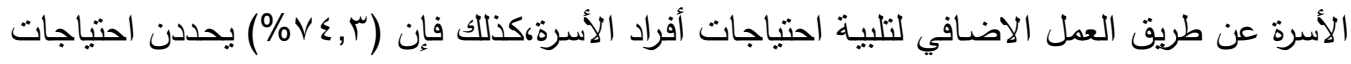

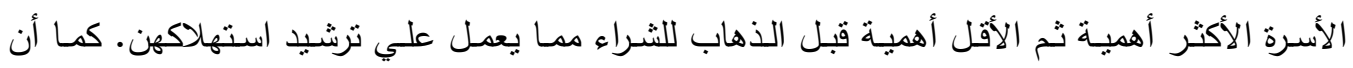

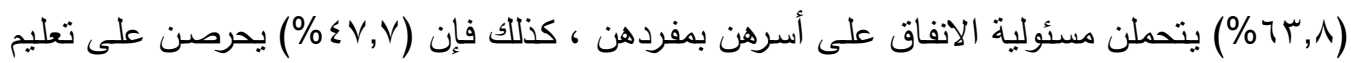

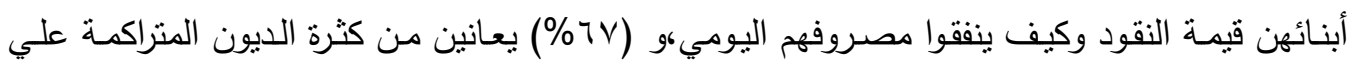
الأسرة. كذلك (0, •0\%) يلجأن إلى بيع بعض الممتلكات الثمينة في حالة وجود أزمات مالية.

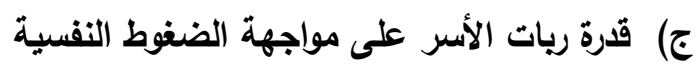
جدول (· () التوزيع النسبي لعينة الدراسة تبعاً لاستجاباتهم على استبيان قدرة ربات الأسر على على مواجهة الضغوط النفسية

\begin{tabular}{|c|c|c|c|c|c|c|c|}
\hline \multicolumn{2}{|c|}{$\bar{\gamma}$} & \multicolumn{2}{|c|}{ آحيانا } & \multicolumn{2}{|c|}{ تانعم } & \multirow[t]{2}{*}{ العبارات } & \multirow[t]{2}{*}{ r } \\
\hline النسبةة & العدد - العد & النسبةة & 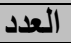 & النسبة & العدد ال العد & & \\
\hline 10,1 & 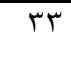 & $\varepsilon V, V$ & $1 \cdot \varepsilon$ & $r v, r$ & $\wedge$ & الابناء الخـات المسـتمرة بينـى وبـين زوجى تـؤثر على نفسية & 1 \\
\hline$\wedge, r$ & 11 & $01, \varepsilon$ & $11 \mathrm{r}$ & $\varepsilon \cdot, \varepsilon$ & $\wedge \wedge$ & اعامل ابنائى بطريقة سوية دون افراط او تدليل & T \\
\hline $1 \wedge, \wedge$ & \&1 & $\varepsilon V, Y$ & $1 \cdot r$ & (T,q & $V \varepsilon$ & يسيطر على الشعور بالوحدة في اغلب الاوقات & r \\
\hline $9, r$ & r. & $r\urcorner, 1$ & Vo & $\neg \leq, V$ & $1 \leqslant 1$ & اشعر بأن هناك فجوة كبيرة بيني وبين زوجى & $\varepsilon$ \\
\hline $1 \leq, V$ & rt & 0 . & 1.9 & ro,r & VV & اتعامل مع المشكلات التى تواجه الأسرة بهدوء وثبات & 0 \\
\hline 17,1 & ro & 0. & 1.9 & req & $V \varepsilon$ & تربية الأبناء تمنل لى عبء كبير من الصعب تحمله & 7 \\
\hline 7,9 & 10 & 71 & ITH & $r+1$ & $\mathrm{~V} \cdot$ & التعامل مع ابنائى بعنف فى بعض الاوقات & $\mathrm{V}$ \\
\hline$\wedge, \vee$ & 19 & rq,^ & 70 & 71,0 & $1 T \leq$ & أشثكو أبنائي للآخرين أمامهم & $\Lambda$ \\
\hline IT,A & rA & $\varepsilon V, r$ & $1 \cdot r$ & $r q, q$ & $\Lambda V$ & من الخاطئة على الحوار الهادىء مـع ابنائى لتوضـح تصـرفاتهم الجيدة & 9 \\
\hline 9,7 & Y) & ऍ人, I & $\Delta r$ & or, r & $11 \varepsilon$ & لا اثق فيما اتخذه من قرارات تخص الأسرة & 1 . \\
\hline 0,0 & IT & 00,0 & $|r|$ & rq & ^o & اعانى من صعوبة التفاهم مع الأبناء & 11 \\
\hline$\wedge, r$ & 11 & $Y 1,1$ & $\varepsilon 7$ & $V \cdot, 7$ & $10 \leqslant$ & الضرورية الخلافات بينى وبين زوجى بسبب عدم توفير بعض حاجاتى & IT \\
\hline $19, \mathrm{~V}$ & $\varepsilon r$ & 0. & $1 \cdot 9$ & $r \cdot r$ & 77 & اشعر بعدم تقدير أفراد اسرتى لمتاعبى & ir \\
\hline Ir, & 广人 & $r V, r$ & $\wedge 1$ & 0. & 1.9 & اشعر بعدم ثقة زوجى فيما اتخذة من قرارات & $1 \varepsilon$ \\
\hline$r, r$ & V & rT, T & $V_{1}$ & $7 \leq, Y$ & $1 \varepsilon$ & اعانى من عدم احترام افراد اسرتى لآرائي & 10 \\
\hline 10,1 & זr & $T V, \varepsilon$ & $1 \leqslant V$ & $1 V, \varepsilon$ & T人 & افقد اعصابى فى الكثير من المواقف داخل الأسرة & 17 \\
\hline$\Gamma, V$ & $\Lambda$ & $r \varepsilon, q$ & $V 7$ & 71,0 & $1 T \leq$ & اشعر بعدم الامن والاستقرار داخل الأسرة & IV \\
\hline$\vee, \wedge$ & $1 \mathrm{~V}$ & 70,1 & $1 \leqslant r$ & $r v, 1$ & 09 & يغضبنى عادات بعض افراد اسرتى & 11 \\
\hline$r r, q$ & or & 00 & Ir. & $r 1,1$ & $\varepsilon 7$ & الثـعر بـالقلق والاضطراب كثيرا قبل قيـامى بـأى عمل من & 19 \\
\hline $09, r$ & 119 & 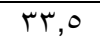 & $V T$ & $\mathrm{~V}, \mathrm{r}$ & 17 & أعانى من الخوف الزائد على أبنائى من أصدقاء السوء & $r$. \\
\hline
\end{tabular}




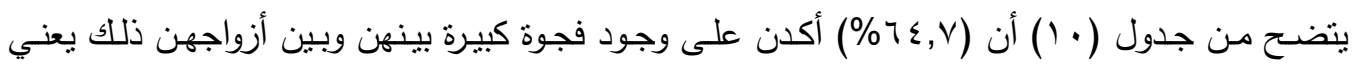

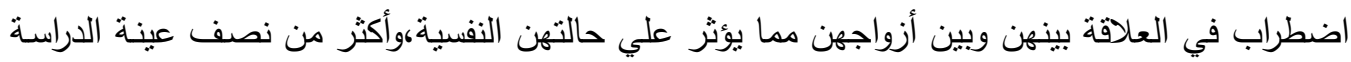

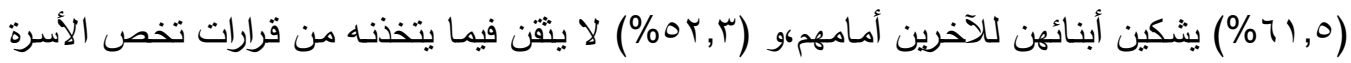

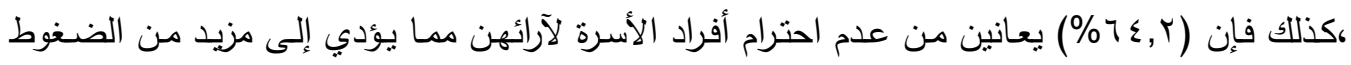
النفسية عليهن.

د) قدرة ريات الأسر على مواجهة الضغوط الصحية جدول (1) التوزيع النسبي لعينة الدراسة تبعاً لاستجاباتهم على استبيان قدرة ربات الأسر على على مواجهة الضغوط الصحية

\begin{tabular}{|c|c|c|c|c|c|c|c|}
\hline \multicolumn{2}{|c|}{$\overline{8}$} & \multicolumn{2}{|c|}{ آحيانا } & \multicolumn{2}{|c|}{ ن تمعم } & \multirow{2}{*}{ العبارات } & \multirow[t]{2}{*}{ r } \\
\hline 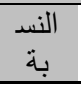 & العدد & 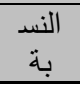 & العدد & 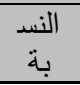 & العدد & & \\
\hline$\Lambda, \vee$ & 19 & H, & $\wedge \varepsilon$ & Or,,$\wedge$ & 110 & طى الاهتمام الكافى للعنايه بنظافة المنزل & 1 \\
\hline 0 & 11 & 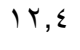 & $r V$ & $\Lambda T, T$ & 11. & انب زوجى فى حاله مرضه & $r$ \\
\hline$r, \wedge$ & 7 & $r V, O$ & 7. & $79, V$ & $10 r$ & اقوم باعداد الوجبات الغذائية السليمه والمنوازنه لابنائى & r \\
\hline$\cdot, 9$ & $r$ & $19, V$ & $\varepsilon r$ & $\vee 9, \varepsilon$ & IVT & اعلم ابنائى بعض السلوكيات الصحيحه الخاصه بتتاول الطعام & $\varepsilon$ \\
\hline 7 & ir & rq, & $\wedge \uparrow$ & $0 \leqslant, 7$ & 119 & اعلم ابنائى خطورة المواد الحافظه والملونه واثارها الصحيه & 0 \\
\hline$r, v$ & $\Lambda$ & $r \wedge, \Sigma$ & $T Y$ & $7 V, 9$ & $1 \leqslant \Lambda$ & 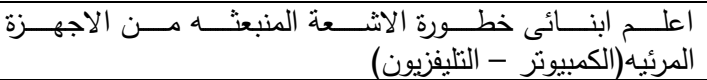 & 7 \\
\hline$v, r$ & 17 & $\varepsilon \varepsilon$ & 97 & $\left.\sum \Lambda,\right\rceil$ & 1.7 & احرص على عمل قائمه طعام صحيه لافراد اسرتى & V \\
\hline$r, r$ & V & rt & $\varepsilon \wedge$ & $7 \vee, 9$ & או & اراعى تنوع الاطعمة ونظافتها عند اعداد الوجبات الغذائيه & $\Lambda$ \\
\hline$q, r$ & $r$. & $r, q$ & 0. & $7 V, 9$ & $1 \leqslant \Lambda$ & اجرى بعض الاسعافات الاوليه لابنائي فى حالة حدوث اصابه & 9 \\
\hline $1, \wedge$ & $\varepsilon$ & $r \cdot r$ & 77 & $\vee 9, \wedge$ & $1 \leqslant \Lambda$ & اهنم بتقديم الطعام بصورة جذابه وبكميات مناسبة & 1. \\
\hline $1, \wedge$ & $\varepsilon$ & $1 \wedge, r$ & $\varepsilon$. & $\vee 9, \wedge$ & $1 V \varepsilon$ & اهتم بالنظافة الشخصية لابنائى قبل وبعد وأثتاء الأكل & 11 \\
\hline$\varepsilon, 7$ & 1. & $\varepsilon \vee, V$ & $1 \cdot \varepsilon$ & $\varepsilon \vee, V$ & $1 \cdot \varepsilon$ & والكيف عرص على إنباع أسس اختبـار المواد الغذائية من حيث الكم & IT \\
\hline$r, r$ & V & $\varepsilon 9,1$ & $1 . v$ & $\varepsilon V, V$ & $1 \cdot \varepsilon$ & خارج المنزب مـا بتتاولـه ابنـائى مـن طعـام وامـنعهم مـن تتـاول الطعـام & $1 T$ \\
\hline$r, r$ & 9 & $\varepsilon \neg, \Gamma$ & $1 \cdot 1$ & $\leqslant 9,0$ & $1 \cdot 1$ & أعود ابنائى على عدم الافراط فى تتاول المشروبات المنبهه & $1 \varepsilon$ \\
\hline$\varepsilon, 1$ & TV & $r q, \wedge$ & 70 & $O \vee, \wedge$ & $1 \% 7$ & أعود ابنائى على ممارسة اى نوع من النشاط البدنى حفاظا على & 10 \\
\hline $1 Y, \varepsilon$ & 0 & $1 V, \varepsilon$ & rᄉ & $\Lambda \cdot, r$ & 180 & أهتم بالتهوبـه الجيده والأضـاءه والتدفئه فى المنزل حفاظـا على & 17 \\
\hline$r, r$ & r & q, & $V \varepsilon$ & 00,0 & $|Y|$ & اهتم بفحص مياه الشرب وتطهيرها حفاظا على صحه أسرتي & IV \\
\hline $1 \cdot, 7$ & $r$ & $r 1,1$ & $\varepsilon 7$ & $V V, 0$ & 179 & 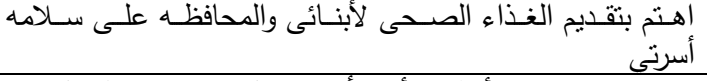 & 11 \\
\hline $1, \varepsilon$ & 1 & $r o, r$ & 00 & $v \varepsilon, r$ & $17 r$ & اهتم بتقديم وجبه الأفطار لأفراد أسرتي قبل خروج من المنزل & 19 \\
\hline$r r, q$ & 0. & rᄉ, I & $\wedge r$ & rq & 10 & الثنجية ابنـائى على مقاومـه الأقبال على الأطعمـه السربعه غير & $r$. \\
\hline
\end{tabular}




\begin{tabular}{|c|c|c|c|c|c|c|c|}
\hline \multicolumn{2}{|c|}{$\bar{y}$} & \multicolumn{2}{|c|}{ أحيانا } & \multicolumn{2}{|c|}{ نعم } & \multirow[t]{2}{*}{ العبارات } & \multirow[t]{2}{*}{ ? } \\
\hline 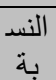 & العدد & 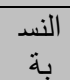 & العدد & 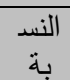 & العدد & & \\
\hline $1, \varepsilon$ & r & r & $\vee q$ & $T r, \varepsilon$ & ד & ألخاطئه أبنـائى العـادات الغذائيـه السـليمه وتجنب العـادات الغذائيـه & YI \\
\hline
\end{tabular}

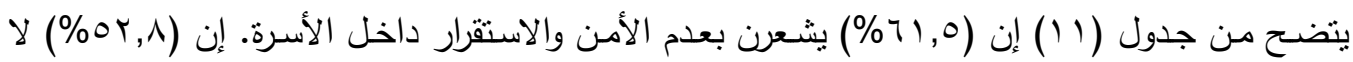

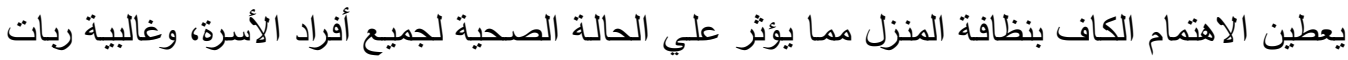

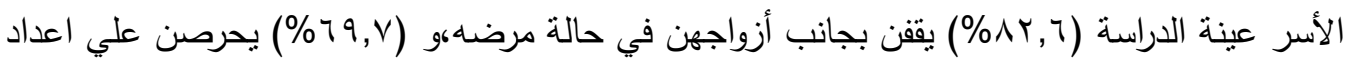

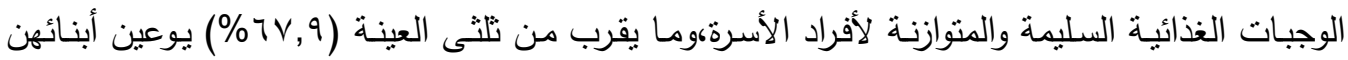

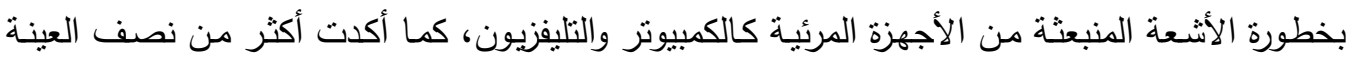
(\%०V,1) أبنائهن على مقاومة الاقبال على الأطعمة السريعة غير الصحية. هـ قارة ريات الأسر على مواجهة الضغوط الاينية والأخلاقية الإلية

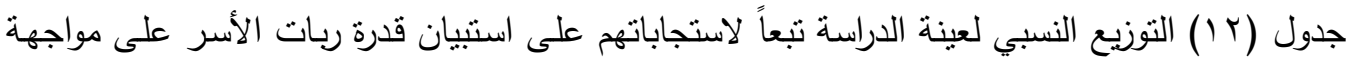
الضغوط الدينية والأخلاقية

\begin{tabular}{|c|c|c|c|c|c|c|c|}
\hline \multicolumn{2}{|c|}{$\overline{\mathrm{y}}$} & \multicolumn{2}{|c|}{ 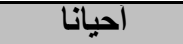 } & \multicolumn{2}{|c|}{ نعم } & \multirow[t]{2}{*}{ العبارات } & \multirow[t]{2}{*}{ 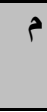 } \\
\hline النسبة - النية & 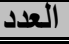 & 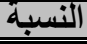 & اللعدد & النسبة - الن & 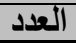 & & \\
\hline $1, \varepsilon$ & r & $1 \mathrm{~T}, \Lambda$ & r人 & $\wedge 0, \wedge$ & $1 \wedge \mathrm{V}$ & أعدل بعض السلوكيات غير اللائقة على الأبناء & 1 \\
\hline- & - & 10,1 & $\overline{\mu r}$ & $\wedge \varepsilon, 9$ & 110 & اهتم بتعميق الدفاهيم الدينيه والصحية للابناء & $r$ \\
\hline $1, \varepsilon$ & $r$ & $1 \cdot, 1$ & Tr & $\Lambda \wedge, 0$ & 194 & أنمي الوازع الديني وحسن الخلق في نفوس الابناء & $r$ \\
\hline $1, \varepsilon$ & $r$ & $1 \cdot, 1$ & Tr & $\Lambda \wedge, 0$ & 194 & أنمي الضمير الخلقي للابناء ليكون رقيبا ذاتيا من داخلهم & $\varepsilon$ \\
\hline$\cdot, 9$ & r & 11,9 & ry & $\Lambda V, r$ & 19. & احرص علي ارتداء الحجاب امام الاخرين & 0 \\
\hline$r, r$ & 0 & $T \leqslant, Y$ & r & $\Lambda r, 0$ & INY & آغرس في آبنائي التسامح مع الآخرين والعفو عند المقدرة & 7 \\
\hline $1, \varepsilon$ & $r$ & $\Lambda, r$ & 11 & $9 \cdot, \varepsilon$ & $19 \mathrm{~V}$ & اربي الضمير عند ابنائي واقوي الدافع الديني & $\bar{V}$ \\
\hline$r, r$ & 0 & $\Lambda, r$ & 11 & $\wedge 9, \xi$ & 190 & آثنجع أبنائي علي الصدق مهما كانت النتائج & $\wedge$ \\
\hline 0,0 & IT & 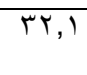 & $\vee \cdot$ & 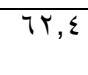 & 114 & أدركهرف ولأخطررهائي لأبنائي حتى يعلموا أنسه خطاً والمهم آن & 9 \\
\hline$\cdot, 9$ & r & $9, Y$ & $r \cdot$ & $\wedge 9,9$ & 197 & أَعلم أبنائي احترام أخواتهم الكبار & $1 \cdot$ \\
\hline$\cdot, 9$ & r & $\Lambda, r$ & 11 & $9 \cdot, \wedge$ & 191 & أعود أبنائي علي احترام الوالدين وتقديم المساعدة لهم & 11 \\
\hline$r, r$ & $\mathrm{~V}$ & $r \cdot, r$ & $\varepsilon \varepsilon$ & $\vee \vee, 7$ & $17 V$ & أغرس في أبنائي حب النعاون مع بعضهم البعض & IT \\
\hline
\end{tabular}




\begin{tabular}{|c|c|c|c|c|c|c|c|}
\hline \multicolumn{2}{|c|}{$\bar{\gamma}$} & \multicolumn{2}{|c|}{ الحيانا } & \multicolumn{2}{|c|}{ نَعم } & \multirow[t]{2}{*}{ العبارات } & \multirow[t]{2}{*}{$\overline{5}$} \\
\hline النسبة & العدد & النسبة & العدد & النسبة & العدد & & \\
\hline$r, r$ & V & $\varepsilon 7, r$ & 1.1 & $0 ., 0$ & 11. & دية الصلاة في جماعة مع أفراد أسرتي & $1 \pi$ \\
\hline$r, r$ & 0 & YO,V & 07 & VY & $10 \mathrm{~V}$ & على الأشتراك فى حل مشكلاتهم وتتميه ثقتهم & $1 \varepsilon$ \\
\hline$\checkmark, \Lambda$ & IV & $r \Lambda, 0$ & $\Lambda \varepsilon$ & Or,, & $11 \mathrm{~V}$ & 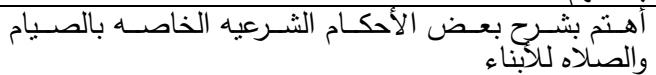 & 10 \\
\hline $7, \varepsilon$ & $1 \varepsilon$ & ro, r & 00 & $T \Lambda, \Gamma$ & $1 \leqslant 9$ & 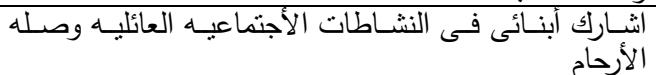 & 17 \\
\hline$r \varepsilon, q$ & $V 7$ & $1 \leqslant, V$ & re & $0 ., 0$ & 11. & ألراقتتبت ابنائى وأتعرف على المواقع التى يدخلون البها عبر & IV \\
\hline $1 \cdot, 7$ & rT & Or,r & $11 \varepsilon$ & $r V, r$ & AI & 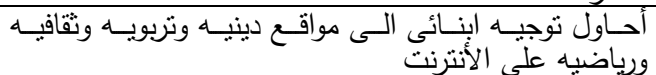 & 11 \\
\hline$\checkmark, \Lambda$ & IV & $\varepsilon r, \tau$ & 90 & $\varepsilon \wedge, \uparrow$ & 1.7 & 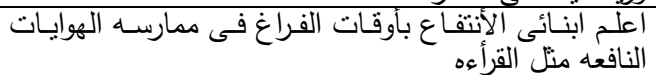 & 19 \\
\hline $1 \cdot, 1$ & TY & $r, r$ & 71 & $\Delta \wedge, \mathrm{V}$ & 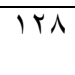 & 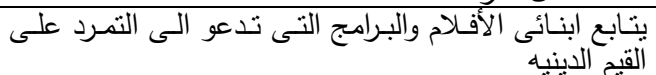 & r. \\
\hline
\end{tabular}

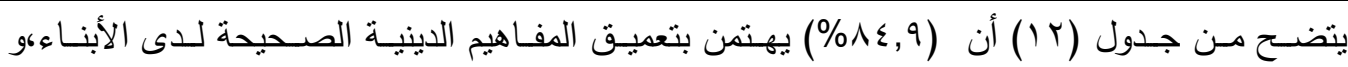

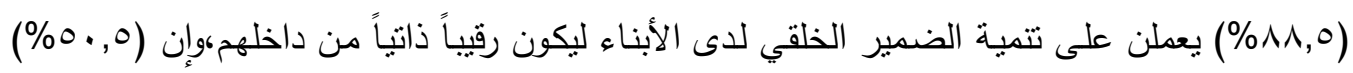
يراقبن أبنائهن ويتعرفن على المواقع التي يدخلون عليها عبر الانترنت، كذلك فإن (O^,〉) يتابع أبنائهن الأفلام والبرامج التي تدعو الى التمرد علي القيم الدينية والأخلاقية والعنف.

و) استجابات ريات الأسر على استبيان مواجهة الضغوط الأسرية جدول (T) التوزيع النسبي لعينة الدراسة تبعاً لمستوي قدرة ربة الأسرة على مواجهة الضغوط الأسرية

\begin{tabular}{|c|c|c|}
\hline النسبة المئوية & العـدد & مستوي قُرة ربة الآسرة على مواجهة الضغوط الآسرية" \\
\hline r 1,1 & $\varepsilon 7$ & مستوي منخفض (Y) \\
\hline$\overline{V \theta, r}$ & $17 \xi$ & مستوي متوسط (Y (Y (Y) \\
\hline $\mathrm{r}, \mathrm{V}$ & $\Lambda$ & 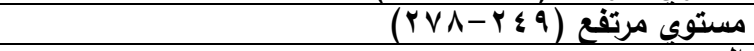 \\
\hline $1 \cdots$ & YIN & المجموع \\
\hline
\end{tabular}

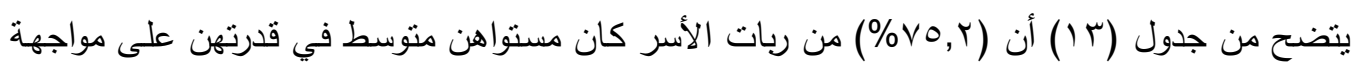

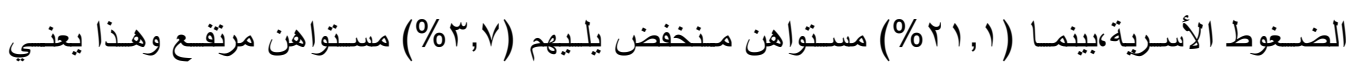
انخفاض نسبة ربات الأسر القادرة على مواجهة وحل المشاكل والضغوط الأسرية التي تواجهها.

ثالثاً : التتائج في ضوء الفروض: النتائج فى ضوء القرض الأول:

ينص الفرض الاول على انه "توجد علاقة ارتباطية ذات دالالة احصائية بين مهارات الاتصال بمحاورها مـع الآخرين - مـع الزوج- مـع الأبنـاء) وقدرة ربـة الأسـرة على مواجهة الضـغوط الأسـرية بمحاورهـا (اجتماعية- اقتصادية- نفسية- صحية- دينية واخلاقية)". 
وللتحقق من صحة الفرض احصائياً نم حساب معاملات الارتباط بطريقة بيرسون بين مهارات الاتصال بمحاورها وقدرة ربة الأسرة على مواجهة الضغوط الضغوض الأسرية بمحاورها. جدول (ع () معاملات ارتباط بيرسون بين مهارات الاتصال بمحاورها وقدرة ربة الأسرة على مواجهة الضغوط الأسرية.

\begin{tabular}{|c|c|c|c|c|c|c|}
\hline الضغخوطة & واخلاضية دية & صحية & نقسية & اقتصادية & اجتماعية & المتغيرات \\
\hline$* * *, r \vee v V$ & ****, r r r & $* * *, r \vee q$ & $* * *, r>0$ & $* * *, r \leq r$ & $\cdot, \cdot V Y-$ & الآخرين \\
\hline$* * *, 191$ & $\cdot, 1 \cdot r$ & $* *, 17 \wedge$ & $*, I Y V$ & $\cdot, \cdot r-$ & $* * *,, 1 \wedge \neg$ & مع الزوج \\
\hline ****,,$\Sigma Y Y$ & $* * *,, \Sigma \Sigma Y$ & ****, ¿ \V &., $.0 Y$ & $* * *, 199$ &., .90 & مع الابناء \\
\hline$* * *,, \leq 7 \vee$ & $* * *, r \leq r$ & $* * *, \Gamma \wedge \wedge$ & $* * *,, r \leq 7$ & ***, & • & الاتهـــارات \\
\hline
\end{tabular}

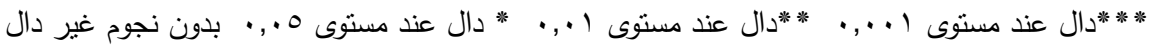

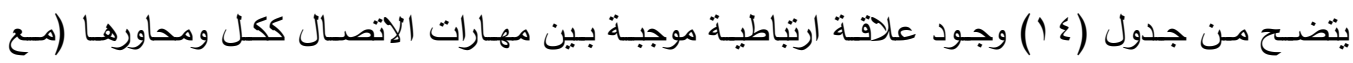
الآخرين - مـع الزوج- مـع الأبناء) ومستوى قدرة ربـة الأسـرة على مواجهة الضـوط الأسرية ككل عند

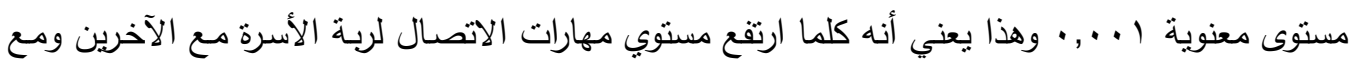
الزوج ومع الأبناء كلما ارتفعت قدرتها على مواجهة الضغوط الأسرية. كما بتضح وجود علاقة ارتباطية

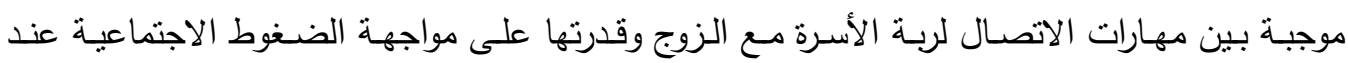
مستوى دلالة ا +.., . أي أنه كلما مهارة اتصال الزوجة مع الزوج كلما زادت قدرة الزوجة على مواجهة الضغوط الاجتماعية التي تتعرض لها. كما يتضح وجود علاقة ارتباطية موجبة بين مهارات الاتصـال لربة الأسرة مع الآخرين ومع الأبناء وبين قدرتها علي مواجهة الضغوط الاقتصادية التي تتعرض لها عند مستوى دلالة ا . ., . أي انه كلما ارتفعت مهارات اتصسالها مـع الآخربن ومهع أبنائها كلما زادت قدرتها على مواجهة الضغوط الاقتصادية. كما ينضـح وجود علاقة ارتباطية موجبة بين مهارات الاتصال لربة الأسـرة مـع الآخرين وقدرتها على مواجهة الضـغوط النفسية عند مستوى دلالـة ا +.., . وبين مهارات الاتصـال لربة الأسرة مع الزوج وقدرتها على مواجهة الضغوط النفسية عند مستوى دلالة هـ ـ. .أى أنه كلمـا زادت مهـارات الاتصـال لربـة الأسـرة مـع الآخـرين ومسع الـزوج كلمـا زادت قدرتها على مواجهـة الضغوط النفسية التي تتعرض لها.كما يتضـح وجود علاقة ارتباطية موجبـة بين مهارات اتصـال ربـة

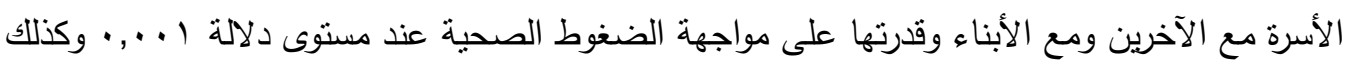

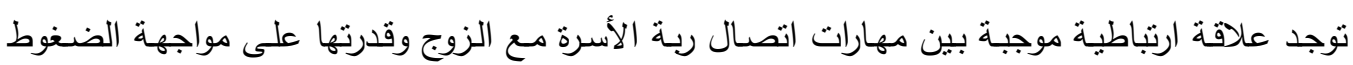
الصحية عند مستوى دلالة ا • , • أي أنه كلما زادت مهارات الاتصال لدى ربة الأسرة كلما زادت قدرتها 
على مواجهة الضغوط الصحية وذلك لأنه عن طريق اتصالها بمصادر متعددة تحصل علي معلومات وفيرة عن العناية بصحتها وصحة أفراد أسرتها. كما يتضح وجود علاقية الفونة ارتباطية موجبة بين مهارات

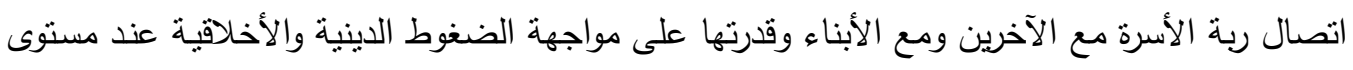

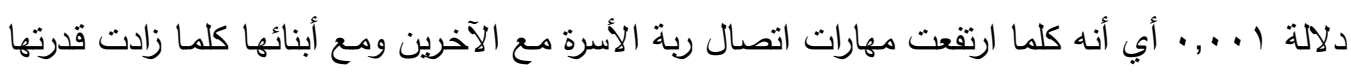

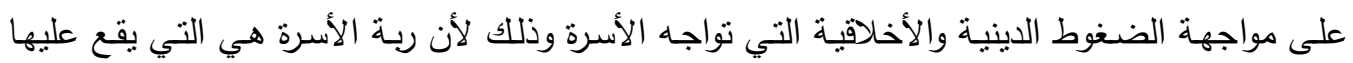
العبء الأكبر في تربية أبنائها. ومما سبق يتضح وجود علاقلاقة ارتباطية موجبة ذات دلالة بين مهارات

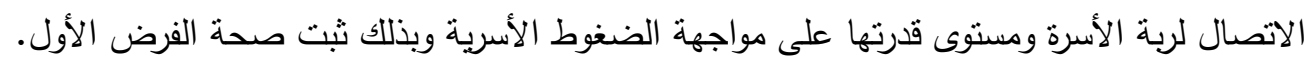

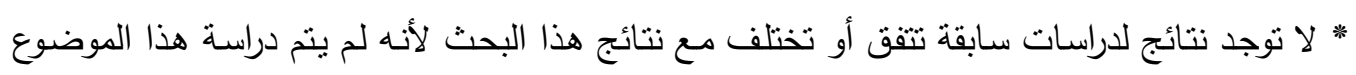
من قبل بشكل كاف.

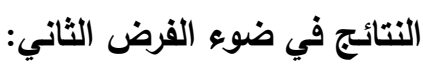

ينص الفرض الثاني على أنه "توجد علاقة ارتباطية ذات دلالية إحصائية بين مهارات الاتصال لربـة

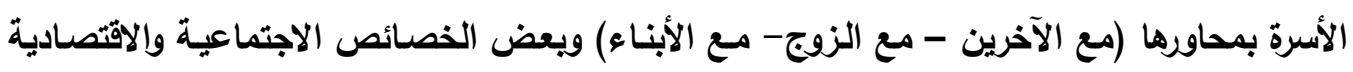
لكلأسر عينة الاراسة " وللتحقق مـن صـحة الفرض إحصـائياً تم حسـاب معـاملات الارتبـاط بطريقة بيرسـون بين مهارات الاتصال بمحاورها وبعض الخصائص الاجتماعية والاقتصادية للأسر عينة الدراسة.

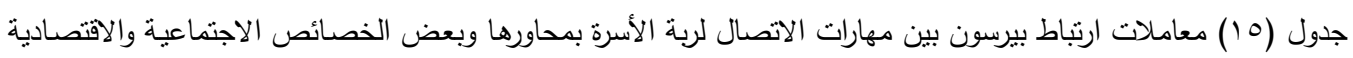
لمألسر عينة الدراسة.

\begin{tabular}{|c|c|c|c|c|c|c|}
\hline عدد أفراد الأسرة & الزوجئة & الزونيم & عمر الزوجة & الزوجر & الزواجة & \\
\hline$* *,, 171-$ & $\cdot, \cdot Y Y-$ & $\cdot, \cdot 10-$ & $\cdot, 11 \cdot-$ & $\cdot, 1 \cdot 1-$ & $\cdot, 1 \cdot V-$ & مع الاخرين \\
\hline$* * * \cdot, \mid \wedge \wedge-$ & $\cdot, \cdot T r$ & $\cdot, \cdot$ rY- & $* * *, Y Y Y V-$ & 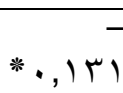 & $\cdot, \cdot \wedge Y-$ & مع الزوج \\
\hline$* *, 170-$ & $\cdot, ., 77$ & $\cdot, \cdots 1$ & $\cdot, .00-$ &., $.0 \mathrm{~V}-$ & $\cdot, \cdot 7 V-$ & مع الأبناء \\
\hline ****, YYYー & $\cdot ., 10$ & $\cdot, \cdot Y I-$ & ${ }^{* * *} \cdot, 177-$ & 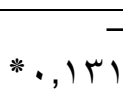 & $\begin{array}{r}- \\
*, 1<\varepsilon\end{array}$ & الأتصــــــالرات \\
\hline
\end{tabular}

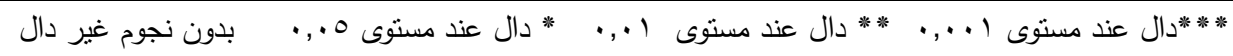

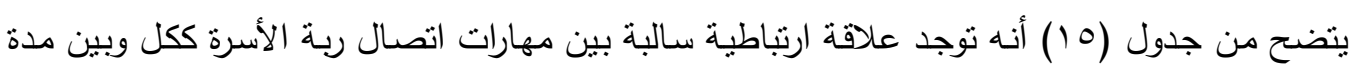

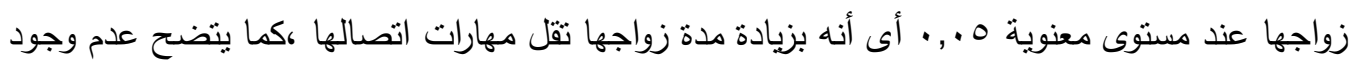

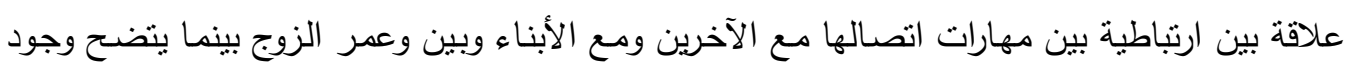

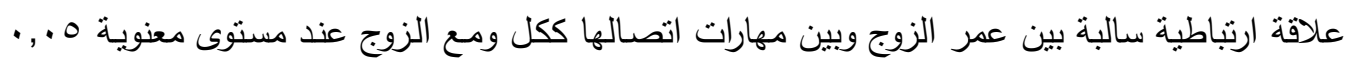


أى أنه كلما كبر الزوج في السن تقل مهارات الاتصـال لاى زوجته معه. كما يتضح أنه نوجد علاقة

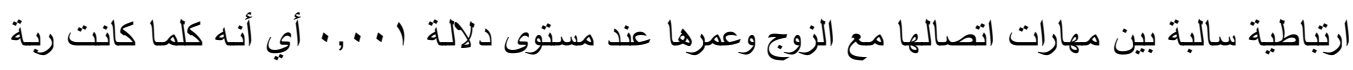

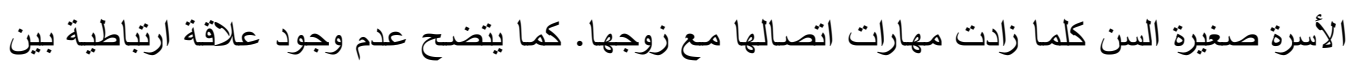

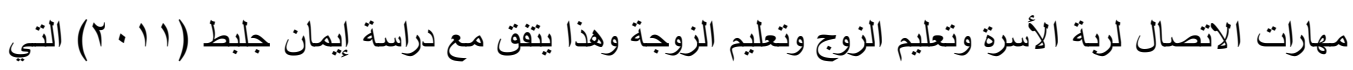

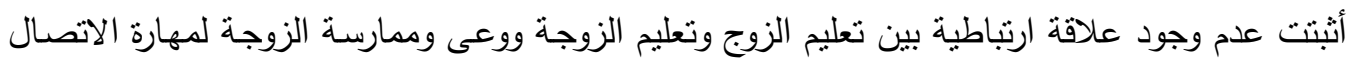

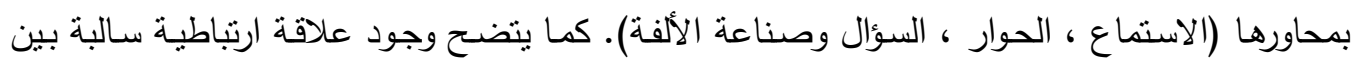

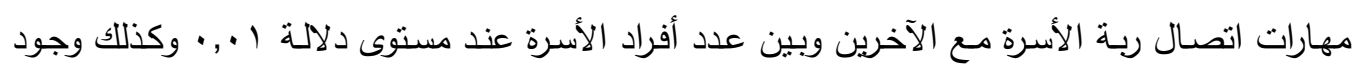

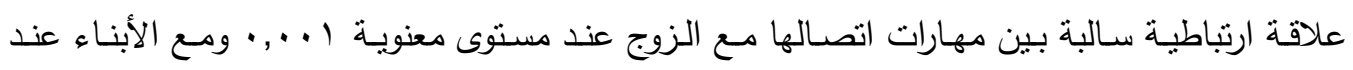

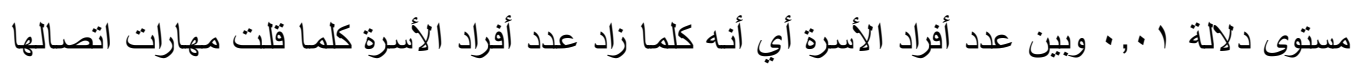

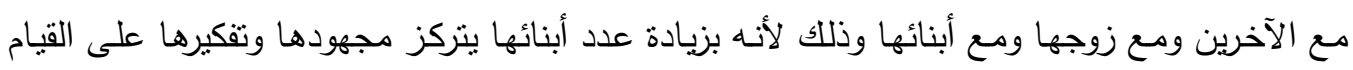

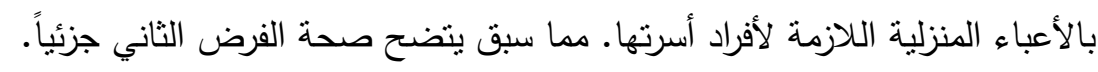
النتائج فى ضوء الفرض الثالث:

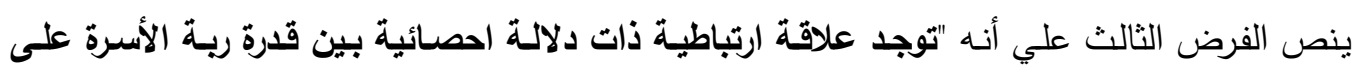

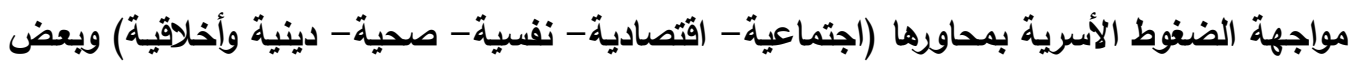
الخصائص الاجتماعية والاقتصادية للأسر عينة الدراسة".

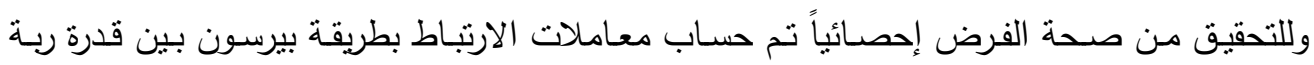
الأسرة على مواجهة الضغوط الأسرية بمحاروهاوبعض الخصائص الاجتماعية والاقتصادية للأسر عينة

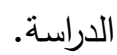
جدول (7 (1) معاملات ارتباط بيرسون بين قدرة ربـة الأسـرة على مواجهة الضغوط الأسرية بمحاورها وبعض الخصائص الاجتماعية والاقتصادية للأسر عينة الدراسة.

\begin{tabular}{|c|c|c|c|c|c|c|}
\hline الأسرية & دينية & صحية & نفسية & اقتصادية & اجتماعية & تغضرات \\
\hline$\cdot, \cdot \vee \vee 9-$ &., .70 & $\cdot, \cdot \leq \Gamma-$ & $\cdot, \cdot V Y-$ & $\cdot, 1 \cdot r-$ & $\cdot, .99-$ & مدة الزواج \\
\hline$\cdot, .79-$ & $\cdot, .9 \leq$ & $\cdot, \cdot, V-$ & $\cdot, .94-$ & $* *, 17 r-$ & $* *, 1 \leq r-$ & عمر الزوج \\
\hline r & 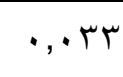 & $\cdot, \cdot \leq Y-$ & $\cdot, \cdot 7 \wedge-$ & $* \cdot, 117-$ & $* * * *, \mid \wedge 7-$ & عر الزوجة \\
\hline$\cdot, \cdot \wedge \Gamma$ & $\cdot, \cdot \vee \vee \wedge$ & $\cdot, .99$ & $\cdot, \cdot, 1 \wedge$ & $\cdot, \cdot, Y I-$ & $\cdot, \cdot, 7 \Lambda$ & تعليم الزوج \\
\hline$* \cdot, I Y Y$ & $\cdot, .90$ & ***, ,, $1 \Gamma \wedge$ & $\cdot, \cdot, T$ & $\cdot, \cdots 9$ & $\cdot, 11$. & تعليم الزوجة \\
\hline$\cdot, \cdot 9 \leqslant-$ & $\cdot, \cdot \leq \vee-$ & $\cdot, 1 \cdot r-$ & $\cdot, \ldots r-$ &., $.01-$ & $\cdot, \cdot V 1-$ & الأسرةدة أفــراد \\
\hline
\end{tabular}

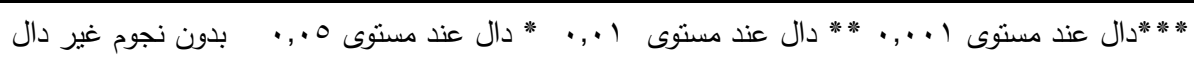


يتضح من جدول (7 () أنه توجد علاقة ارتباطية سالبة بين قدرتها على مواجهة الضغوط الاجتماعية

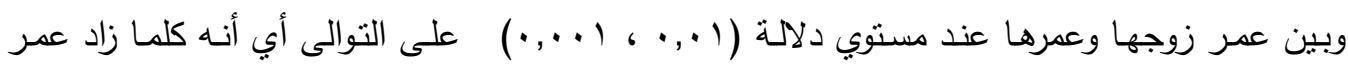
الزوج والزوجة كلما قلت قدرتها على مواجهة الضغوط الاجتماعية التي تعترض حياتها. كما يتضح عدم وجود علاقة ارتباطية بين قدرة ربة الأسرة علي مواجهة الضغوط الاقتصـادية وبين مدة الزواج ومستوى تعليمها وتعليم زوجها وعدد أفراد أسرتها وهو ما يختلف مع دراسـة زينب حقي (991 ( ) التي أثـارت إلى أن المستويات التعليمية لرب وربة الأسرة معا تساهم في رفع مستوى التخطيط المالي وغيرها وكذلك خفض الشعور بصراع الدور لدى ربات الأسر العاملة. بينما توجد علاقة ارتباطيه سالبة بين قدرة ربة الأسرة على مواجهة الضغوط الاقتصادية وبين عمر الزوج وعمرها عند مستوي دلالة( ( .,. ، 0 •, •) على الترتيب أي انه كلما زاد سن الزوج والزوجة كلما قلت قدرتها علي مواجهة علي مواجهة الضـوط الاقتصسادية وذلك لانه بزيـادة سن الزوج تقل قدرته على العمل الاضـافي لزبادة دخل الأسرة وكذلك بوصسوله لسـن المعـاث ينخفض راتبـه كثيـراً باعتباره المسئول الأول عـن توفير المـوارد الماديـة للأسرة.

كما يتضح وجود علاقة ارتباطية موجبة بين قدرة ربة الأسرة علي مواجهة الضغوط الصحية وبين مستوي تعليمها عند مستوي دلالة ا • ,. . أي أنه كلما ارتفع مستوي تعليمها زادت قدرتها على مواجهة الضغوط الصحية وذلك لزيادة معلوماتها وثقافتها بزيادة مستوى تعليمها. كما يتضـح وجود علاقة ارتباطية سالبة بين قدرة ربة الأسرة على مواجهة الضغوط الأسرية وبين عمرها عند مستوى دلالة ه . ,. أى أنه كلما زاد عمر الزوجة كلما انخفضت قدرتها على مواجهة الضغوط الأسرية وذلك لأن ربة الأسرة تتحمل وحدها كثير من الأعباء الأسرية مما يعمل على زيادة الضغط الجسدي والمعنوي عليها مما لاتستطيع تحمله في الكبر كما توجد علاقة ارتباطية موجبة بين قدرة ربة الأسرة على مواجهة الضغوط الأسرية وبين مستوى تعليمها عند مستوى دلالـة ه . , • أى أنـه كلمـا ارتفع مستوى تعليمها كلمـا زادت قدرتها على مواجهة الضـوط الأسـرية لأن مستوى تعليمها وثقافتها يتيح أمامها العديد من البدائل عند مواجهة أى مشكلة تخص الأسرة مما يساعدها على اتخاذ القرار السليم.مما سبق يتضح تحقق الفرض الثالث جزئياً.

\section{النتائج فى ضوء الفرض الرابع:}

ينص الفرض الرابع علي أنه" توجد فروق ذات دلالة إحصائية في مستوى مهارات الاتصال لربة الأسرة وقدرتها على مواجهة الضغوط الأسرية تبعاً لاخل الزوجة".

One Way وللتحقق من صحة الفرض إحصائيا تم استخدام اختيار تحليل التباين في اتجاه واحد Anova وقدرتها على مواجهة الضغوط الأسرية تبعاً لدخلها. 
جدول (V) تحليل التباين في اتجاه واحد لمهارات الاتصال لربة الأسرة وقدرتها على مواجهة الضغوط الأسرية تبعاً لاخلها ن= \اب

\begin{tabular}{|c|c|c|c|c|c|c|}
\hline مستّوي & 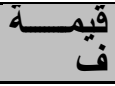 & متوبيداث & الزحبية & مانميعاث & ر التباين & \\
\hline \multirow[t]{3}{*}{$\cdot, \cdot 1$} & \multirow[t]{3}{*}{$r, V \leqslant \varepsilon$} & pq, & 7 & $r \cdot T V, V V \varepsilon$ & بين المجموعات & \multirow{3}{*}{ مهــارلت } \\
\hline & & \multirow[t]{2}{*}{ ITr,V70 } & YI & 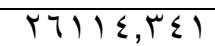 & داخل المجموعات & \\
\hline & & & TIV & Y人IOY,I10 & & \\
\hline \multirow[t]{3}{*}{$\cdot, \cdot 0$} & \multirow[t]{3}{*}{$1, \wedge \varepsilon r$} & $\varepsilon \cdot V, r q \varepsilon$ & 7 & 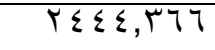 & بين المجموعاث & \multirow{3}{*}{ 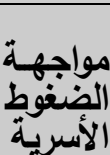 } \\
\hline & & \multirow[t]{2}{*}{ r } & YI & י & داخل المجموعات & \\
\hline & & & YIV & $59111, .97$ & & \\
\hline
\end{tabular}

يتضح من جدول (V) ) أنه توجد فروق ذات دلالة إحصائية بينٍ متوسط درجات ربات الأسر عينة الدراسة في مهارات الاتصـال بمحاورها تبعا للاخلها حيث بلغت النسبة النهائية المعبرة عن هذا الفرق

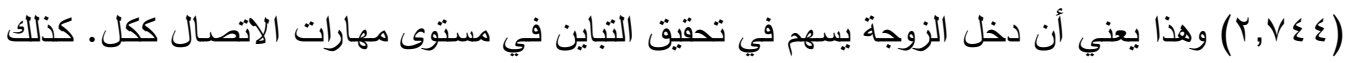

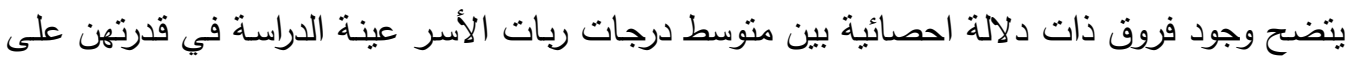

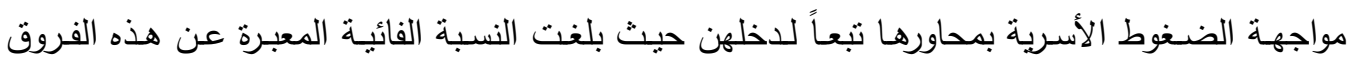

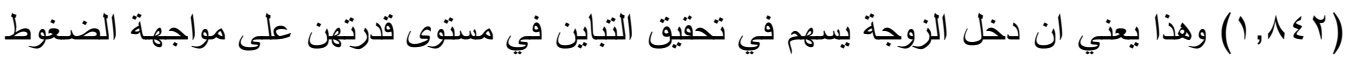
الأسرية ككل. جدول (1) الحليل L.D.D لمعرفة أقل فرق معنوي واتجاه الفروق في مهارات الاتصال لدى ربة الأسرة والضغوط الأسرية التي نواجهها تبعا لدخلها

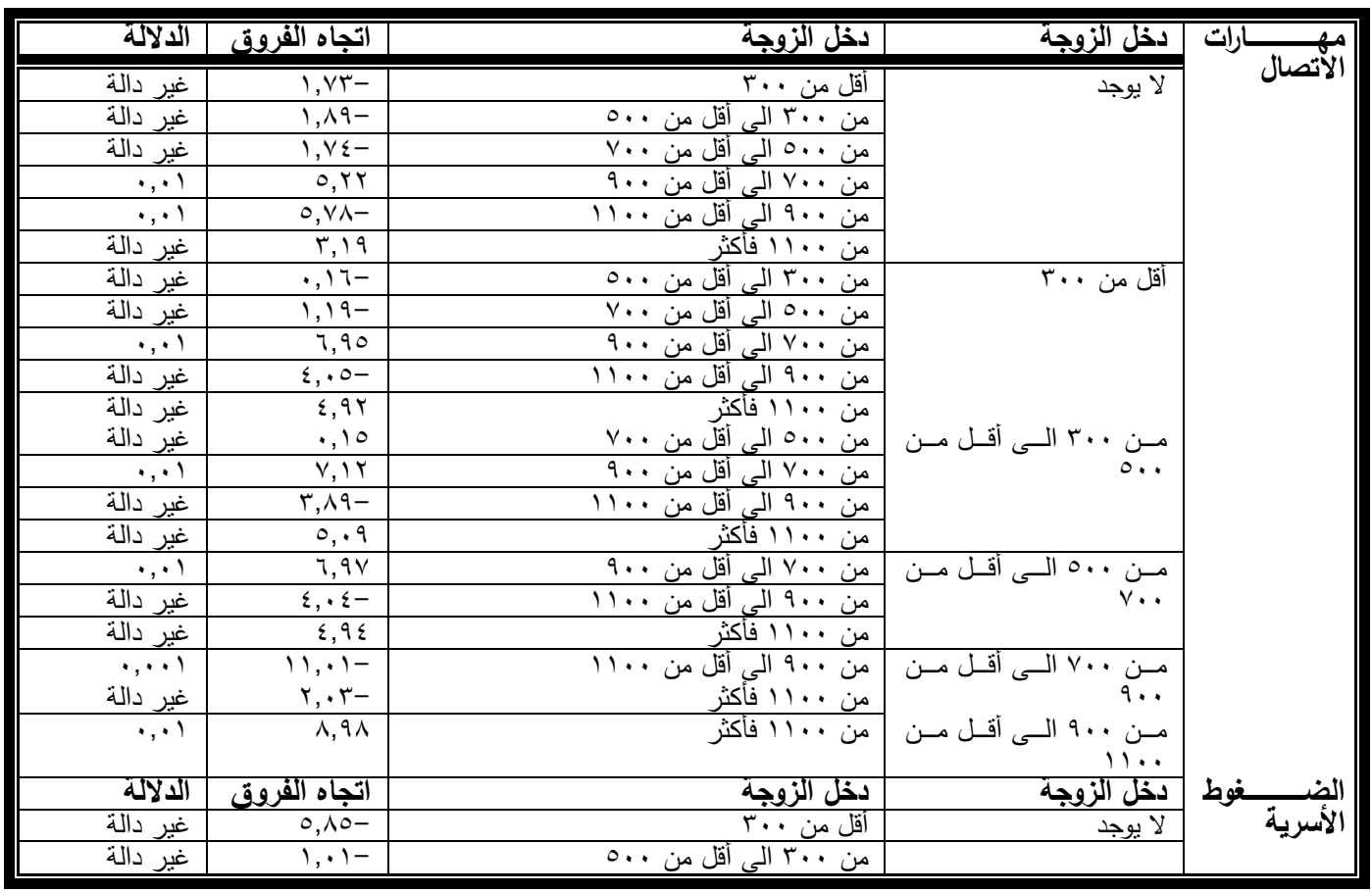




\begin{tabular}{|c|c|c|c|}
\hline غير دالة & $\cdot, r q-$ & 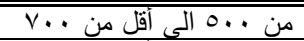 & \\
\hline$\cdot, .0$ & $0,7 Y$ & من · • اللى أقل من · . & \\
\hline غير دالة & $\varepsilon, 0$ r- & 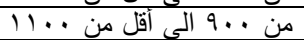 & \\
\hline غير دالة & $r, 9 V$ & من . . 11 فأكثر & \\
\hline غير دالة & $\varepsilon, \wedge r$ & من · . اللى أقل من · . & أقل من ... \\
\hline غير دالة & $0, \sum 7$ & 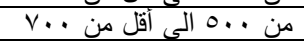 & \\
\hline$\cdot, \cdots 1$ & $11, \varepsilon \wedge$ & من · • اللي أقل من · . & \\
\hline غير دالة & $1, r Y$ & 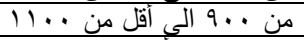 & \\
\hline., .0 & $q, \wedge \mu$ & من . . 11 فأكثر & \\
\hline غير دالة & $\cdot, 7 Y$ & 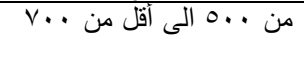 & 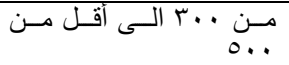 \\
\hline$\cdot, .0$ & $7,7 \varepsilon$ & من · • اللى أقل من . . & \\
\hline غير دالة & $r, 01-$ & من · . 9 الىي أقل من . 11 & \\
\hline غير دالة & $\varepsilon, 99$ & من · • إتكثر & \\
\hline غير دالة & $T, \cdot Y$ & من · . اللى آقل من . . & 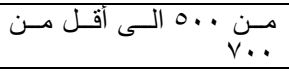 \\
\hline غير دالة & $\varepsilon, 1 Y-$ & من · .9 الى أقل من · 11 & \\
\hline غير دالة & $\varepsilon, \mu V$ & من · ، 1ا فأكثر & \\
\hline$\cdot, \cdot 1$ & $1 \cdot, 17-$ & من · .9 اللى آقل من 11 & 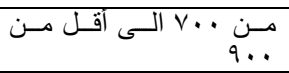 \\
\hline غير دالة & $1,70-$ & من · ، 11 فأكثر & \\
\hline$\cdot, \cdot 0$ & 1,01 & من · • ا أكثر & 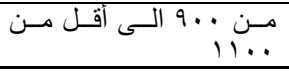 \\
\hline
\end{tabular}

يتضح من جدول (1) (1) بحساب L.S.D لمعرفة أقل فرق معنوي واتجاه الفروق في مهارات الاتصال

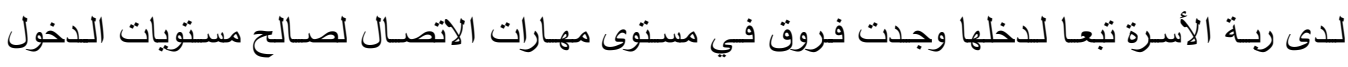

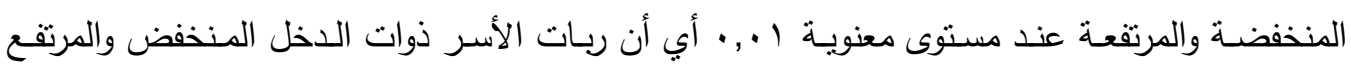

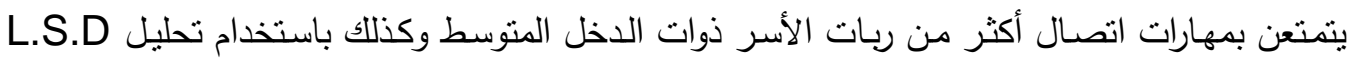

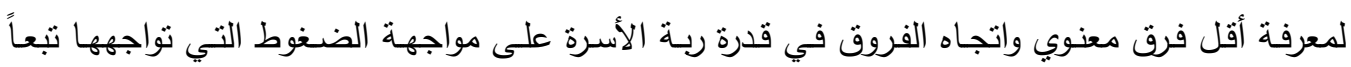

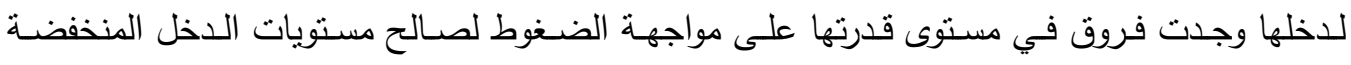
والمرتفعة عند مستوى دلالة ه .. . أي أن ربات الأسر ذوات مستويات الدخول المنخفضة والمرتفعة أكثر

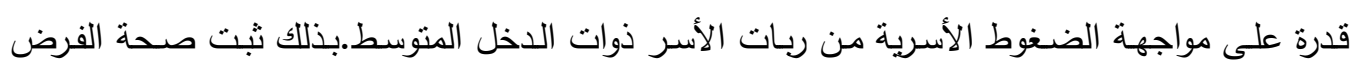
الرابع.

\section{التوصيات في ضوء النتائج: أ- توصيات خاصة بربة الأسرة:} 1 - الاهتمام بتتمية مهارات الاتصال مـع الزوج ومـع الأبناء ومع الآخرين لأنها من أكثر الوسائل التي

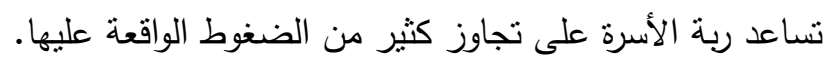
r- الاهتمام بتتمية المورد المالي لمساعدتها على تجاوز الضغوط الإنير الاقتصادية الواقعة عليها.

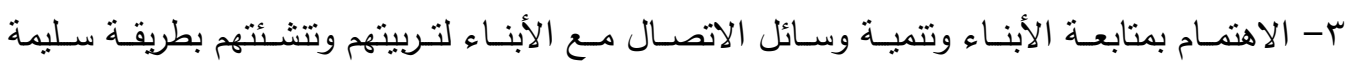
ومساعدتهم على مواجهة الضغوط الدينية والأخلاقية الواقعة عليهم. ب- توصيات خاصة بالمؤسسات المجتمعية المسئولة التي تقلم خدماتها لريات الأسر : 
1- تقديم البرامج الارشادية التي تساعد ربة الأسرة على تتمية مهارات اتصالها مع الزوج والأبناء والآخرين.

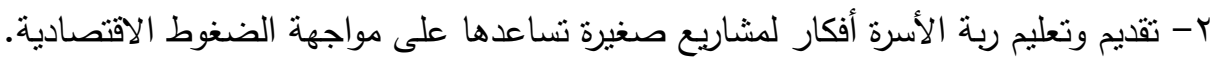
r- تقديم التوعية اللازمة لربة الأسرة لمساعدتها على تربية وتتشئة الأبناء ومواجهة الضغوط الدينية والأخلاقية.

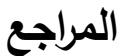

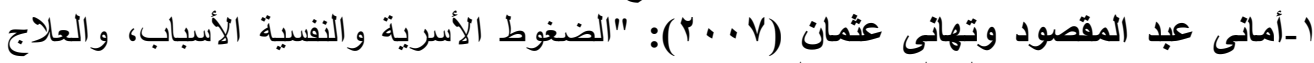
المكتبة الانجلو المصرية القاهرة.

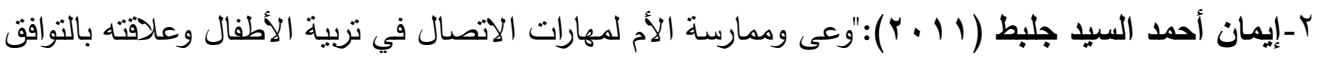

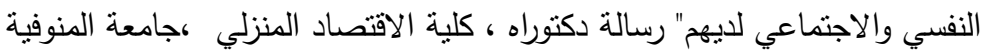

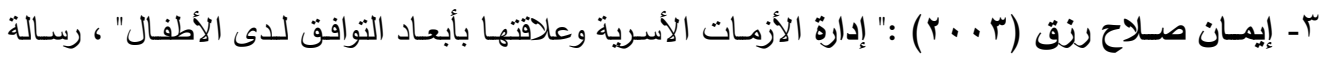

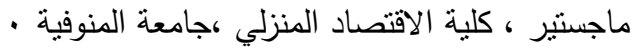

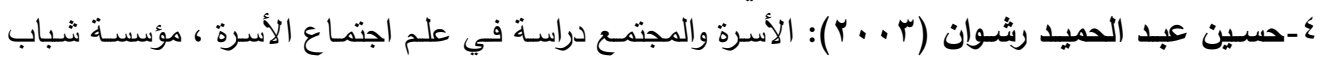
الجامعة ، الإسكندرية.

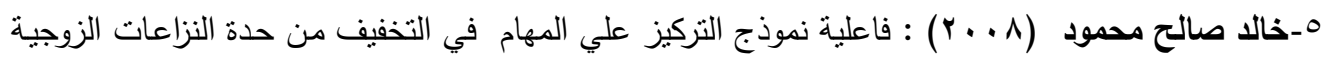

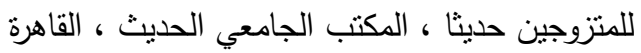

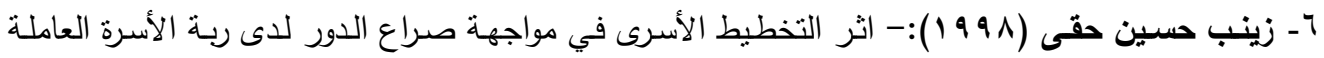

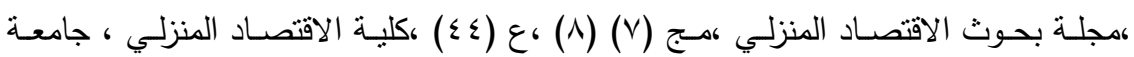
المنوفية

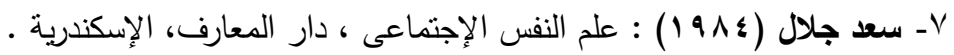

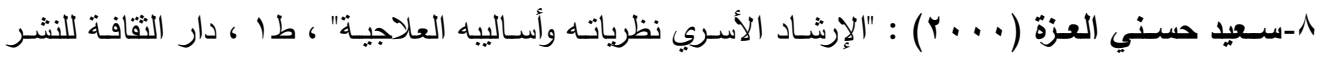
والتوزيع ، الأردن.

9 - السيد عبد العاطى ومحمد أحمد بيومى وسامية محمد جبر وحسن محمد حسن ونادية عمر والسيب رثـاد

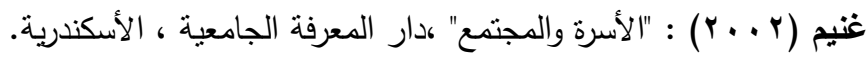

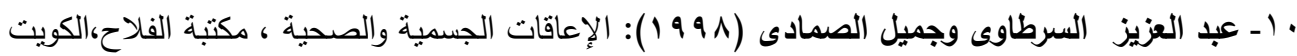

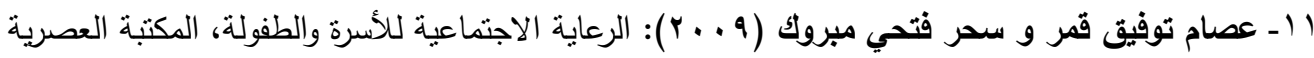

$$
\text { اللنشر والتوزيع ، المنصورة. }
$$

rا - علاء الدين كفافى (99 9 (1) ) : الأسرة علاج التفاعلات الأسرية ، التنخيص ، مجلة علم النفس ، الهيئة

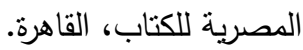

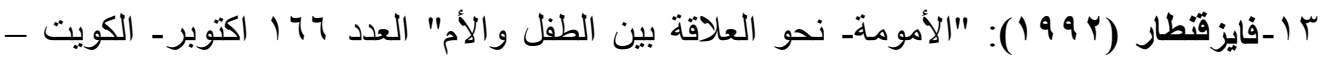

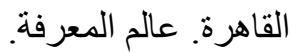

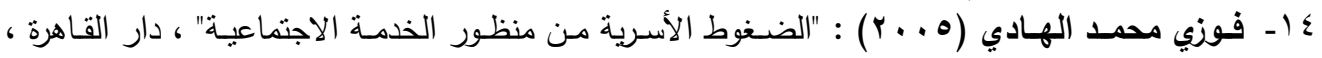
القاهرة. 10 ـ محمد محمد الثيخ (900 (99) ): وحده تكامل المعاملة الأسرية وعلاقتها بالتوافق النفسي للأبناء ، مجله

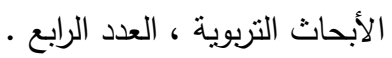

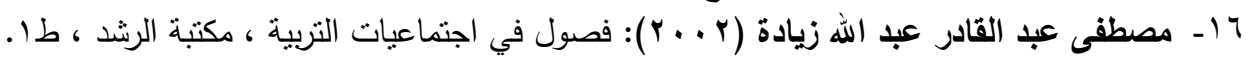


1- sheran Christina, P (1999): Caregiver-child social communication: effects of mother-child interactions child development in the home.

r- singer, Elly (2001): The logic of young children's (non vebal ) behavior, paper presented at the European conference on quality in earh childhood education (11th, Alkmaar, nether Lands, August, 29- sep 1,2001).

r- Thompson, R.H. \& Wayne, F. (1998): "Establishing disriminative control of responding using functional and alternative reinforces during functional communication training". Journal of Applied Behavior Analysis. Vol. 31. No. (5) p.p. (993- 60)

\& - Tuaker, R. \& philip, J. (1999): "How adult beliefs sape the speech communities of child who has multiple disabilities ", Journal of mental Retardation Vol. 37 No. (6) p.p. (393- 406). 


\section{Abstract \\ Communication skills and it's relation with mother of the family's ability to face the familial pressures Preparation \\ Dr. Amira Hassan Abdel good Dawam \\ Lecture of Home Management and institutions Faculty of Home \\ Economics Menofia University

\author{
Dr. Noha Abdel-Sattar Abdel- \\ Mohsen \\ Lecture Of Home Management and \\ Institutions, Faculty of Home \\ Economics, Menofia University
}

The man in almost all of his cases needs to connect to other humans that the individual is born with the need to communicate and it continues with him throughout his life. The family sensation by pressures, suffering and their ability to confront problems is influenced by the individual characteristics of its members, such as : individuals intelligence degree, style of their thinking, their personal traits and the nature of relations prevailing between them as it is influenced also by its organization and structure mode, as by comparing the families that the mothers live alone by the families that the mothers and fathers live together it is shown that the mother is better capable of facing the problems in the presence of the father but the presence of the father itself is not enough to alleviate the familiar suffering where it is a must for his effective and serious participation and bearing responsibility and providing assistance and support to the mother to be possible to alleviate feeling by pressures, so the research targets studying the relationship between communication skills and the ability of housewife to face multiple familial pressures. Public data form of the housewife, a communication skills questionnaire and a familial pressures facing questionnaire were used, the questionnaire has been applied on a sample of 218 housewives from Menofia province. The results revealed the presence of correlation between communication skills and the ability of housewife to face familial pressures, and the presence of statistically significant differences in communication skills and the familial pressures facing according to the variables of the study (place of residence - marriage duration - the educational level of the husband and wife - wife's work - family size). 